Arabian Journal for Science and Engineering

ISSN: 2193-567X (print version); ISSN: 2191-4281 (electronic version)

Publisher- Springer; Impact factor $=1.518$

ACCEPTED MAY 25TH 2020

\title{
COMPUTATION OF METALLIC NANOFLUID NATURAL CONVECTION IN A TWO- DIMENSIONAL SOLAR ENCLOSURE WITH RADIATIVE HEAT TRANSFER, ASPECT RATIO AND VOLUME FRACTION EFFECTS
}

\author{
Sireetorn Kuharat ${ }^{1 *}$, O. Anwar Bég ${ }^{1 * *}$, Ali Kadirl ${ }^{* * *}$ and B. Vasu ${ }^{2 * * * *}$ \\ ${ }^{1}$ Aeronautical \& Mechanical Engineering Department, School of Computing, Science and \\ Engineering, Newton Building, University of Salford, Manchester, M54WT, UK.
}

${ }^{2}$ Department of Mathematics, MNNIT Allahabad, Prayagraj, Uttar Pradesh-211004, India.

*Email-S.Kuharat@edu.salford.ac.uk

**Email: O.A.Beg@salford.ac.uk; gortoab@gmail.com

****Email: $\underline{\text { A.Kadir@salford.ac.uk }}$

\begin{abstract}

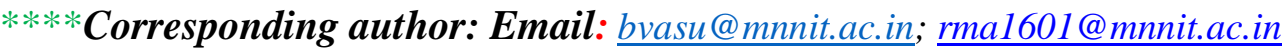

As a model of nanofluid direct absorber solar collectors (nano-DASCs), the present article describes recent numerical simulations of steady-state nanofluid natural convection in a two-dimensional enclosure. Incompressible laminar Newtonian viscous flow is considered with radiative heat transfer. The ANSYS FLUENT finite volume code (version 19.1) is employed. The enclosure has two adiabatic walls, one hot (solar receiving) and one colder wall. The Tiwari-Das volume fraction nanofluid model is used and three different nanoparticles are studied (Copper $(\mathrm{Cu})$, Silver $(\mathrm{Ag})$ and Titanium Oxide $\left(\mathrm{TiO}_{2}\right)$ ) with water as the base fluid. The solar radiative heat transfer is simulated with the P1 flux and Rosseland diffusion models. The influence of geometrical aspect ratio and solid volume fraction for nanofluids is also studied and a wider range is considered than in other studies. Mesh-independence tests are conducted. Validation with published studies from the literature is included for the copperwater nanofluid case. The P1 model is shown to more accurately predict the actual influence of solar radiative flux on thermal fluid behaviour compared with Rosseland radiative model. With increasing Rayleigh number (natural convection i.e. buoyancy effect), significant modification in the thermal flow characteristics is induced with emergence of a dual structure to the circulation. With increasing aspect ratio (wider base relative to height of the solar collector geometry) there is a greater thermal convection pattern around the whole geometry, higher temperatures and the elimination of the cold upper zone associated with lower aspect ratio. Titanium Oxide nano-particles achieve slightly higher Nusselt number at the hot wall compared with Silver nano-particles. Thermal performance can be optimized with careful selection of aspect ratio and nano-particles and this is very beneficial to solar collector designers.
\end{abstract}

KEY WORDS: Nanofluid; solar enclosure; metallic nano-particles; computational fluid dynamics (CFD); natural convective heat transfer; thermal radiation; Isotherms; Streamlines; vortex; aspect ratio.

\section{NOTATION}




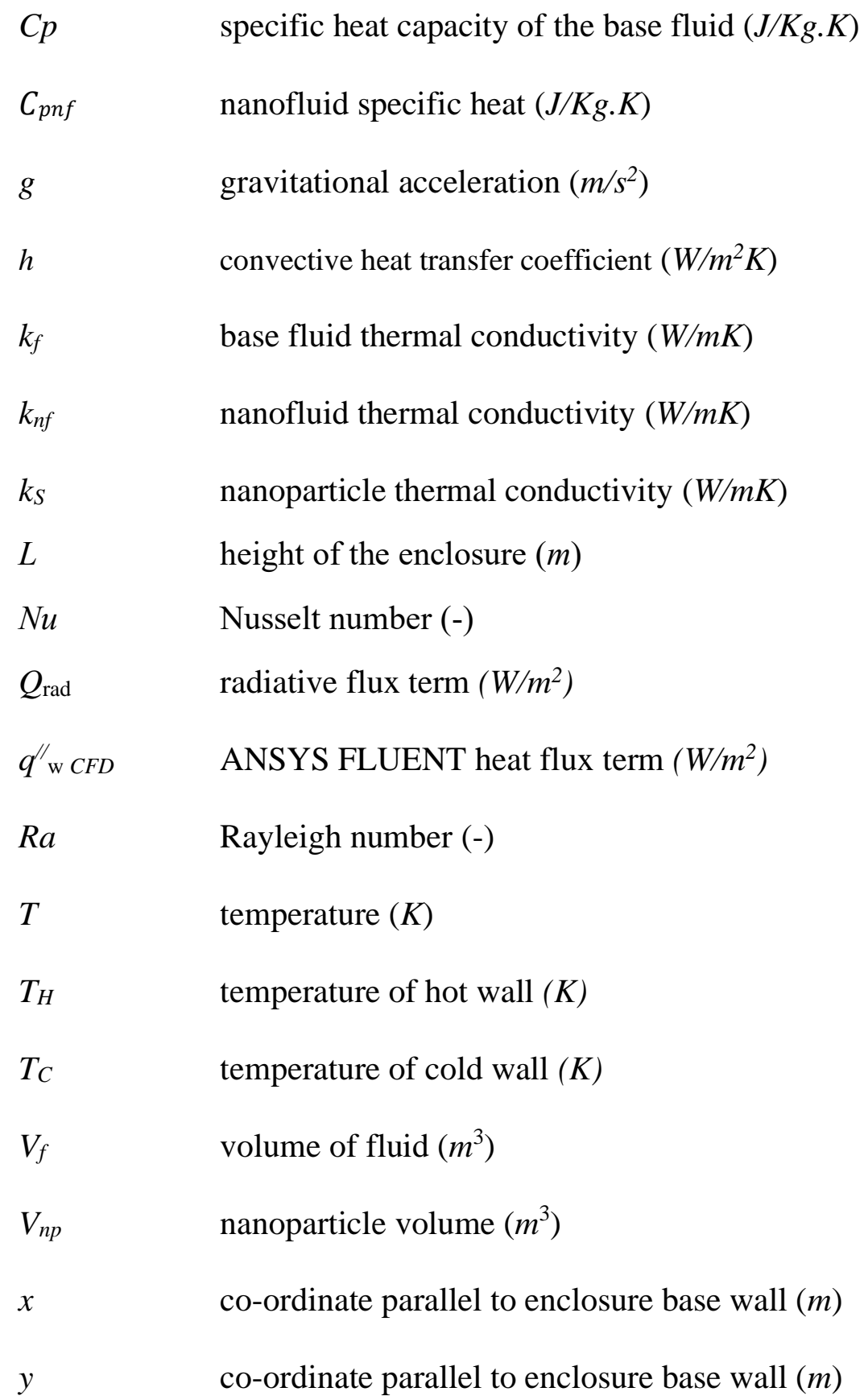

\section{Greek}

$\begin{array}{ll}\alpha_{m} & \text { thermal diffusivity }\left(\mathrm{m}^{2} / \mathrm{s}\right) \\ \beta & \text { coefficient of thermal expansion, } \alpha_{m} \text { is thermal diffusivity } \\ \Delta T & \left.\text { temperature difference between the hot and cold walls (i.e. } T_{H}-T_{C}\right) \\ \phi & \text { volume fraction of nanoparticles in base fluid (water) } \\ \mu_{n f} & \text { dynamic viscosity of nanofluid }(\mathrm{kg} / \mathrm{m} . \mathrm{s}) \\ \mu_{f} & \text { dynamic viscosity of base fluid (water) }(\mathrm{kg} / \mathrm{m.s})\end{array}$




$\begin{array}{ll}\rho & \text { density }\left(\mathrm{kg} / \mathrm{m}^{3}\right) \\ \rho_{n f} & \text { nanofluid density }\left(\mathrm{kg} / \mathrm{m}^{3}\right) \\ \rho_{f} & \text { base fluid density (water) }\left(\mathrm{kg} / \mathrm{m}^{3}\right) \\ \rho_{s} & \text { metallic nanoparticle density }\left(\mathrm{kg} / \mathrm{m}^{3}\right)\end{array}$

\section{INTRODUCTION}

Nanofluids were introduced by Choi [1] as a mechanism for enhancing thermal properties of engineering fluids such as water, air and oil. A nanofluid comprises a colloidal mixture of a small quantity of conducting nanoparticles suspended in a base fluid, such as water. Nanofluids have been shown to exhibit high, non-linear and anomalous thermal conductivity, compared to the base fluid and to achieve significant elevations in heat transfer rates in either free (natural) or forced convection. Nanofluid dynamics involve four scales: the molecular scale, the microscale, the macroscale and the mega-scale and an interaction is known to take place between these scales. Diverse types of nanofluids can be synthesized by combining different nano-particles (e.g. metallic oxides, silicon carbides, carbon nanotubes) with different base fluids. An elaborate description of the numerous manufacturing methods developed for robust and stable nanofluid suspensions has been provided in Das et al. [2]. Engineers have explored many applications of nanofluids which have aimed at manipulating the structure and distribution of nanoparticles to modify macroscopic properties of the nanofluid such as its thermal conductivity. Recent examples of the implementation of nanofluids in energy and other applications include automobile radiator systems [3] (Silver nanoparticles dispersed in distilled water), drilling muds [4] (titanium oxide and aluminium oxides in bentonite base fluid), IC cycle marine gas turbine intercoolers (copper and alumina nano-particles in air) [5], separation and purification of biological molecules and cells [6] (gold nano-particles), pharmacodynamics [7] (silver and gold nano-particles) and PEM fuel cells [8]. Another key area of 
interest for nanofluids is solar engineering. Recently green Titanium oxide nano-particles have been considered for deployment in parabolic trough solar collectors [9] and magnetic iron oxide nano-particles have been studied for solar pumping systems [10]. Among the many systems available for modern solar energy, direct absorption solar collectors (DASCs), compared to conventional collectors, have been found to be simpler and often more efficient since owing to the absence of an absorber plate, thermal resistance is reduced to the path of energy absorption. Direct absorption solar collectors, although employed for many decades in for example water heating however have traditionally yielded low thermal efficiency due to the limited absorption properties of the working fluid (air or water). However, with recent developments in nanofluid technologies, doping of conventional solar collector fluids with metallic nano-particles has shown that significant improvements in working liquid thermophysical properties (e.g. thermal conductivity) and radiative absorption properties are achievable in direct absorption solar collectors [11-13]. Karamia et al. [14] observed substantial thermal enhancement with silverwater nanofluids in field tests of direct solar absorbers. Tyagi et al. [15] studied the performance of water-aluminum nanofluid in a DAC observing that the presence of nanoparticles increases the absorption of incident radiation by more than nine times over that of pure water and nanofluids achieve at least a ten percent better efficiency than conventional water-based flat-plate collectors. Gorji and Ranjbar [16] described experiments on a nanofluidbased direct absorption solar collector (DASC) using graphite, magnetite and silver nanoparticles dispersed in de-ionized water. They observed that magnetite dispersions attained the highest thermal and exergy efficiencies; followed by graphite and silver nanofluids, respectively. Goodson et al. [17] reviewed characteristics of nanofluids relevant to solar and other renewable energy systems including increase in surface volume ratio, Brownian motion, thermophoresis, thermal conductivity enhancement and surveyed a variety of computational and experimental investigations on forced and free convective heat transfer. Bozorgan. and 
Shafahi [18] reviewed a number of studies on design of direct absorber solar thermal systems using nanofluids and working at optimum conditions.

A fundamental configuration of relevance to direct absorber solar collectors is the rectangular enclosure. Many researchers have therefore conducted numerical (and experimental) studies of nanofluid-filled enclosures, in particular with buoyancy (natural convection) effects. Kosti et al. [19] employed a finite element method to simulate buoyancy-driven laminar incompressible flow in a two-dimensional titled rectangular enclosure for the case of copperwater nanofluid with constant heat flux at the left vertical wall and convective boundary condition on the other three walls. They observed that with greater Rayleigh number and inclination angle there is a sizeable elevation in average Nusselt number and that has Nusselt number is highest with low aspect ratio. Ogut [17] used the polynomial differential quadrature (PDQ) method to analyse the free convection heat transfer of water-based nanofluids in an inclined square enclosure where the left vertical side is heated with constant heat flux (with a heat source at the centre), the right side is cooled, and adiabatic conditions are enforced on the other sides. They considered five metallic nanoparticles, copper, silver, copper oxide, aluminium oxide and Titanium oxide. They showed that average heat transfer decreases is depressed with greater heat source length and lower inclination angles but enhanced with both particle volume fraction and Rayleigh number increase. Arani et al. [18] used the finite volume method with a SIMPLER algorithm to simulate the coupled heat and mass transfer in mixed convection of temperature-dependent alumina-water nanofluid in a lid-driven square enclosure. They computed solutions for the case where the temperature and concentration of the left wall are higher than those of the right wall, while the two other walls are adiabatic and impermeable. They considered the influence of Richardson number, buoyancy ratio, nanoparticle volume fractions (up to $4 \%$ ) and observed that with an increment in nanoparticle volume fraction (at high Richardson numbers) there is a depression in average Nusselt number, whereas the 
opposite effect is induced at low Richardson numbers. They also found that for buoyancyassisted flow, higher average Nusselt or Sherwood numbers are achieved and that heat lines are closer for nanofluid than pure water base fluid indicating superior convective heat transfer by nanofluids. Yu et al. [19] employed the Buongiorno nanoscale model and a wavelet homotopy analysis code to analyze the laminar mixed convection flow in an inclined lid-driven nanofluid enclosure flow featuring internal heat generation with sinusoidally heated sidewalls of the enclosure are sinusoidally heated and upper and lower insulated walls. They noted significant modification in heat transfer characteristics and flow behaviour with Grashof number, Brownian motion, thermophoresis, enclosure the inclination and amplitude ratios of temperature and concentration. Ahmed and Eslamian [20] deployed a two-phase lattice Boltzmann computational solver and the Buongiorno nanoscale model to study the laminar natural convection in differentially heated inclined and bottom-heated square enclosure, observing that thermophoresis exerts a major influence on heat transfer augmentation and that heat transfer rate is minimized with bottom heating whereas it is maximized by a unique inclination angle which influences the Rayleigh number. The Tiwari-Das model [21] is an alternative nanoscale formulation to the Buongiorno model. It does not feature a separate nanoparticle species conservation equation but instead modifies the key properties of the doped nanofluid (thermal conductivity, density and viscosity) and allows different types of nanoparticle material to be modelled via more realistic empirical correlations which are formulated in terms of the nano-particle concentration (volume fraction). In this regard it is a much more useful approach for real solar energy direct absorber systems. Sheremet et al. [22] used a second-order accurate finite difference method to investigate computationally the free convection in a square enclosure containing a nanofluid-saturated porous medium for the case of copper and aluminium nano-particles. Muthtamilselvan et al. [23] used a finite volume solver with a staggered grid arrangement to simulate mixed convection in a lid-driven enclosure 
(insulated vertical walls and isothermal horizontal walls) with filled with copper-water nanofluid, noting the sensitivity of heat and momentum transfer characteristics to aspect ratio and solid volume fraction and showing that there is a linear relationship between average Nusselt number and solid volume fraction.

The above studies were confined to thermal convection heat transfer and did not consider radiative heat transfer. In the design of real solar collectors however thermal radiation is a critical consideration. Radiative properties and models must be employed to capture the contribution of solar radiative flux. Sharaf et al. [24] have shown that water-based nanofluids achieve stronger radiation absorption than alternative nanofluids in solar collectors. They have also shown that above a critical nanoparticle volume fraction value, the solar collector performance is no longer significantly influenced. Even with powerful numerical methods (such as those available in ANSYS FLUENT finite volume software), it remains very challenging to simulate the solve the general integro-differential radiative transfer equation (RTE) and this is further complicated when coupled to natural convection. Algebraic flux model approximations are therefore popular in computational studies of combined radiation and convection flows. These include the Rosseland diffusion flux model, P1 flux model, Schuster-Schwartzchild two-flux model and Hamaker six-flux model. For example, in solar collector nanofluid coating simulations, Mehmood et al. [25] recently employed the Rosseland flux model and observed a dramatic increase in heat transfer characteristics in nanofluids when radiation is included. Alternative approaches for modelling radiative effects include Rayleigh scattering. Recently Sharaf et al. [26] studied coupled radiative transfer and convection in a nanofluid-based, direct absorption solar collector (DASC) using a Rayleigh scattering approximation for the optical properties of the nanofluid. They showed that DASC performance is significantly influenced by spectral distribution of the extinction coefficient of the nanoparticles and that. the use of a blackbody incident spectrum over-predicts the thermal 
enhancement performance overestimations for certain types of nanoparticle suspensions (e.g., silver) more than others (e.g., graphite). They also observed that much higher nanoparticle volume fraction results in less substantial increases in the efficiency of the collector with incident radiation. Lee et al. [27] used a Monte Carlo algorithm and finite element analysis to computationally investigate the performance of a direct solar thermal collector using localized surface plasmon of metallic nanoparticles suspended in water. They studied the case of a direct solar thermal collector with four types of gold-nanoshell particles blended in the aquatic solution and observed that blended plasmonic nanofluids can significantly enhance the solar collector efficiency by $70 \%$ with an extremely low particle concentration $(0.05 \%$ particle volume fraction) by dramatically increasing radiative absorption.

Aspect ratio effects in nanofluid solar collectors have been considered by several researchers in recent years and these may involve either the enclosure geometry or the nano-particles themselves or both. Bouhalleb and Abbassi [28] simulated natural convection in inclined cavity filled with $\mathrm{CuO}$-water nanofluid heated from one side and cooled from the ceiling using a finite volume method based on the SIMPLER algorithm. They observed that the impact of Rayleigh number on heat transfer is reduced for a shallow enclosure (aspect ratio less than unity) whereas the influence of aspect ratio is stronger when the enclosure is tall (aspect ratio greater than unity) and the Rayleigh number is high. They also found that as Rayleigh number is elevated, a significant compression of isotherms arises towards the hot wall and the cold upper boundary with the majority of the enclosure being occupied by warmer fluid, leading to an expansion of the single circulation cells, flow distortion and the emergence of boundary layers. Trodi et al. also used a finite volume method to compute heat and flow characteristics in differentially heated square enclosures filled with $\mathrm{Al}_{2} \mathrm{O}_{3}$-water nanofluid also considering the influence of. shapes and aspect ratios of nanoparticles, Rayleigh number, solid and volume fraction. They demonstrated that increasing both nanofluid volume fraction and Rayleigh number boosts the 
heat transfer rate and that oblate and prolate spheroid shaped nanoparticles achieve the best overall heat transfer. Wong et al. [30] used COMSOL finite element software to investigate the effects of mass fraction concentration of nanoparticles (10 and 25\%), enclosure aspect ratio and inclination on natural convection in water-based alumina nanofluid in rectangular enclosures. They also utilized a non-invasive method (ultrasound thermometry) to measure the temperature distribution. They found that multi-cellular enclosure regime is modified to a boundary layer regime at a Rayleigh number of about 10million for an aspect ratio of 2.625 and at 200million when the aspect ratio is 1.0 , for different concentrations of nanofluid. They also noted that instability in the core region is computed and observed at a Rayleigh number of about 12 million and aspect ratio equal to 2.625. Qi et al. [31] used a two-phase lattice Boltzmann model to simulate the natural convection heat transfer in horizontal rectangle enclosures containing Ag-Ga nanofluid (at different nanoparticle volume fractions of $1 \%, 3 \%$, 5\%) and different Rayleigh numbers (100 and 100,000). They also studied Nusselt number enhancement ratios for two geometries of the enclosures (aspect ratio of 2 and 4) noting that the flatter horizontal rectangular enclosure (aspect ratio of 4) has a higher Nusselt number. They also showed that Nusselt number increases with the decreasing nanoparticle radius and that Brownian force and drag force are influenced by enclosure aspect ratio.

In the current study, extensive computational fluid dynamics simulations of steady-state nanofluid natural convection in a two-dimensional enclosure are presented. Incompressible, laminar, Newtonian viscous flow is considered with natural convection and radiative heat transfer. The ANSYS FLUENT finite volume code (version 19.1) [32] is employed. This code has also been used very effectively in recent years to analyse other areas of energy sciences. For example, Atmaca et al. [33] used ANSYS software to investigate 3-dimensional, turbulent, two-phase, multi-component and reacting flow-fields, developed in a diesel evaporator, computing distillation temperatures in diesel fuel for an extensive range of 
scenarios. In the present work, within the ANSYS FLUENT solver framework, the Tiwari-Das volume fraction nanofluid model is used and three different metallic nanoparticles are studied (Copper $(\mathrm{Cu})$, Silver $(\mathrm{Ag})$ and Titanium Oxide $\left.\left(\mathrm{TiO}_{2}\right)\right)$ with water as the base fluid. The solar radiative heat transfer is simulated with the P1 flux and Rosseland diffusion models available in ANSYS. The influence solid volume fraction for nanofluids is also studied and a wider range is considered than in other studies. In addition, geometrical enclosure aspect ratio effects are analysed. Mesh-independence tests are conducted. Validation with earlier simulations by AbuNada and Oztop [34] is also included for the copper-water nanofluid and vertical enclosure (non-inclined) case. Isotherm and streamline distributions are presented for the influence of different solar radiative flux models, Rayleigh number, types of metallic nano-particle (silver, titanium oxide and copper), aspect ratio (ratio of base to height of the solar collector geometry) and nano-particle volume fractions. Interesting thermal and hydrodynamic features are computed. The study may provide further insight into more realistic performance of direct absorber nanofluid solar collector designs and optimum selection of aspect ratio, nano-particle volume fraction and nano-particle type for maximizing heat transfer characteristics. Furthermore, the results of the present investigation will be useful in designing laboratory experiments in the near future [35].

\section{COMPUTATIONAL THERMO-FLUID DYNAMIC MATHEMATICAL MODEL}

The direct absorber solar collector geometry considered is visualized in Fig. $\mathbf{1}$ in an $(x, y)$ coordinate system. Solar radiative flux is received on the left-hand wall (hot wall). There is no heat transfer though the top wall (adiabatic end condition). No slip boundary conditions are assumed on all walls of the enclosure (cavity). The walls are solid (impermeable). Metallic nano-particles are homogeneously dispersed in the base fluid (water) and are in local thermal 
equilibrium. The physical properties of the fluid assumed constant. The physical model is shown in Fig. 1. Laminar, steady-state, incompressible flow is analysed with natural convective heat transfer. The conservation equations i.e. time-independent Navier-Stokes equations, in a Cartesian coordinate system, take the following form:

\section{D'Alembert mass conservation (2-D continuity)}

$$
\left[\frac{\partial u}{\partial x}+\frac{\partial v}{\partial y}\right]=0
$$

\section{$x$-direction momentum conservation}

$$
\rho_{f}\left[u \frac{\partial u}{\partial x}+v \frac{\partial u}{\partial y}\right]=\rho_{f} F_{x}-\frac{\partial p}{\partial x}+\mu_{f}\left[\frac{\partial^{2} u}{\partial x^{2}}+\frac{\partial^{2} u}{\partial y^{2}}\right]-g[1-\beta \Delta T]
$$

\section{$y$-direction momentum conservation}

$$
\rho_{f}\left[u \frac{\partial v}{\partial x}+v \frac{\partial v}{\partial y}\right]=\rho_{f} F_{y}-\frac{\partial p}{\partial y}+\mu_{f}\left[\frac{\partial^{2} v}{\partial x^{2}}+\frac{\partial^{2} v}{\partial y^{2}}\right]
$$

\section{Energy conservation}

$u \frac{\partial T}{\partial x}+v \frac{\partial T}{\partial y}=\alpha_{m}\left(\frac{\partial^{2} T}{\partial x^{2}}+\frac{\partial^{2} T}{\partial y^{2}}\right)+Q_{r a d}$

Here $(u, v)$ are velocity components in the $(x, y)$ directions, $\alpha_{m}=\frac{k_{f}}{\rho_{f} C_{p}}$ is the thermal diffusivity, which is a measure of thermal inertia and $k_{f}=$ fluid thermal conductivity $(\mathrm{W} / \mathrm{mK}), \rho_{f}=$ density $\left(\mathrm{kg} / \mathrm{m}^{3}\right), C p=$ specific heat capacity of the nanofluid $(\mathrm{J} / \mathrm{Kg} . \mathrm{K})$. When $\alpha_{\mathrm{m}}$ is high, the heat moves fast and the nanofluid conducts heat quickly (higher thermal conductivity). $T$ denotes temperature $(K),-g[1-\beta \Delta T]$ is the thermal buoyancy force (featured in the $x$-momentum equation which couples this equation with the energy equation, where $\Delta T$ is the temperature difference between the hot and cold walls (i.e. $T_{H}-T_{C}$ ) and $Q_{\mathrm{rad}}$ is the radiative heat flux. ANSYS FLUENT software [32] provides a solar load model (for both steady and time- 
dependent flows) which may be implemented to compute the radiation effects from the sun rays entering the computational domain; however, the solar load model is only available for 3dimensional modelling. In the present simulation, the Rosseland and P1 algebraic flux models are therefore employed to simulate radiative heat transfer via the radiative flux term, $Q_{\text {rad }}$. The principal focus is to study the heat absorption capability of various types of nanofluids. The solar radiative flux is therefore fixed in the $y$-direction (imposed on the hot left wall) with a specific intensity of $877 \mathrm{~W} / \mathrm{m}^{2}$. The solar calculator utility in ANSYS FLUENT (solar load model) is de-selected. To simulate nano-particle effects, the Tiwari-Das model [21] is employed which allows different concentrations (volume fraction) and types of metallic nanoparticles to be simulated. In ANSYS, this approach is implemented as a "one-phase flow" modification since the particles are very small. A nanofluid is defined in the ANSYS FLUENT workbench as a new fluid with a new density, viscosity, thermal conductivity and specific heat obtained as a function of a base fluid and nano-particle type and concentration (volume fraction. The volume fraction can be estimated from:

$$
\phi=\frac{\mathrm{v}_{\mathrm{np}}}{\mathrm{vf}}
$$

Where $\phi=$ volume fraction, $V_{n p}=$ nano particles volume and $V_{f}=$ volume of fluid. The dynamic viscosity can be estimated from:

$$
\mu_{\mathrm{nf}}=\frac{\mu \mathrm{f}}{(1-\phi)^{2.5}}
$$

Here $\mu_{n f}=$ dynamic viscosity of nanofluid (kg/m.s), $\mu_{f}=$ dynamic viscosity of base fluid. The effective density and heat capacity also can be estimated from:

$$
\begin{gathered}
\rho_{\mathrm{nf}}=(1-\phi) \rho f+\phi \rho s \\
\mathrm{C}_{\mathrm{pnf}}=\frac{(1-\phi)(\rho \mathrm{Cp}) \mathrm{f}+\phi(\rho \mathrm{Cp})}{\rho_{n f}},
\end{gathered}
$$


Here $\rho_{n f}=$ nanofluid density, $\rho_{f}=$ base fluid density, $\rho_{s}=$ nanoparticle density, $C_{p n f}=$ nanofluid specific heat. The effective thermal conductivity of fluid can be determined by the MaxwellGarnet relation which is adopted in Tiwari and Das [21]:

$$
\frac{\mathrm{Knf}}{\mathrm{kf}}=\frac{\mathrm{ks}+2 \mathrm{kf}-2 \phi(\mathrm{kf}-\mathrm{ks})}{\mathrm{ks}+2 \mathrm{kf}-\phi(\mathrm{kf}-\mathrm{ks})}
$$

Here $k_{n f}=$ nanofluid thermal conductivity, $k_{f}=$ fluid thermal conductivity and $k_{S}=$ nanoparticle thermal conductivity. All calculated nanofluid properties (for the three different metallic nanoparticles studied i.e. copper oxide, silver and titanium oxide) at the two volume fractions studied are given in the Appendix. The key local dimensionless parameters which may be computed in ANSYS FLUENT [32] are local Rayleigh number (ratio of thermal buoyancy and viscous hydrodynamic force) and the Nusselt number (heat transfer rate along the left wall). These may be defined as:

Rayleigh number: $R a_{y}=\frac{g \beta}{V \alpha m}(\Delta T) y^{3}$

Nusselt number: $N u=\frac{h L}{k n f}=\frac{q_{w C F D}^{\prime \prime}(L)}{k n f(\Delta T)}$

Here $g$ denotes is gravity, $\beta$ is coefficient of thermal expansion, $\alpha_{m}$ is thermal diffusivity, $y$ is coordinate, $h$ is convective heat transfer coefficient, $B$ is the width of the enclosure, $L$ is height of the enclosure (aspect ratio $A R=L / B), q_{w C F D}^{\prime \prime}$ is the heat flux rate computed in ANSYS FLUENT. In addition to no-slip boundary conditions at the walls of the enclosure, the following thermal boundary conditions are imposed:

Left wall: Constant temperature, $T=390 \mathrm{~K}$

Right wall: Constant temperature, $T=290 \mathrm{~K}$

Top and Bottom walls: Adiabatic

Radiative heat transfer is also incorporated using the ANSYS P1 model and Rosseland radiative models. The Rosseland radiation model assumes that the intensity is the black-body intensity 
at the nanofluid temperature. The standard thermal conduction flux is augmented with the radiative flux, $Q_{\text {rad }}$. The Rosseland model is simpler but less realistic than the Trauggott P1 differential since the latter is not restricted to optically thick fluid media. However significantly higher mesh density is required for the P1 model. Both models are available in ANSYS with the pressure-based solver, which is therefore deployed in the present computations.

\section{ANSYS FLUENT GRID SENSITIVITY ANALYSIS}

Quadrilaterals ("quad") elements have been used in the meshing process. As an example, the square enclosure case is shown i.e. aspect ratio, $A R=1$ in Fig. 2. Quad elements are commonly used in simple geometries to reduce simulation times. Fig. 3 illustrates the grid sensitivity analysis which shows that the simulations for heat flux at the wall attain mesh-independent convergence with approximately 20,000 elements i.e. with progressive increase in element density from several thousand, to 5000, 1000, 15,000 and eventually 20, 000 elements there is no tangible modification in the heat flux which converges to a constant value. A mesh density fo 20,000 elements is therefore of adequate quality for computations. To validate the results obtained from the ANSYS Model for natural convection inside a 2-D enclosure filled with copper-water nanofluid, with a Rayleigh number of $10^{3}$, a comparison (numerical benchmark) is conducted with the earlier study of Abu-Nada and Oztop [34] for an aspect ratio of 1 (square enclosure) as shown in Fig. 4 a,b. The CFD simulation, using ANSYS FLUENT achieves close correlation with the results in [34] as testified to by the similarity in streamline and isotherm contour patterns. Other test cases were also conducted (not shown for brevity) to further confirm confidence in the ANSYS FLUENT model. Once confidence was established in the simulations further new simulations could be performed to examine specific effects of aspect ratio, Rayleigh number (buoyancy), different metallic nanoparticles and radiative flux models. 


\section{RESULTS AND DISCUSSION}

The ANSYS FLUENT results are depicted in Figs. 5-23. Figs 5 a-c illustrate temperature contour (isotherm) plot computations with different radiative flux models, for Silver-water nanofluid with low volume fraction $=0.01(1 \%)$, for a square enclosure $(A R=1)$ with Rayleigh number, $R a=10^{4}$ and radiative absorption coefficient of 0.2 . Silver water nanofluid is studied since it has proved very promising for achieving high heat transfer rates and silver has the advantage of anti-microbial properties and requiring less maintenance than other metallic nanoparticles [35]. Roy et al. [36] have also confirmed experimentally that silver-water nanofluids achieve improved heat transfer even at relatively low volume fractions (less than 5 $\%)$ although they considered only flat plate solar collectors. In the present study a solar flux is specified of $877 \mathrm{~W} / \mathrm{m}^{2}$ which is also consistent with the solar radiation flux values examined by Roy et al. [36] (among others) who considered the range $800 \mathrm{~W} / \mathrm{m}^{2}$ to $1000 \mathrm{~W} / \mathrm{m}^{2}$. Ozsoy and Corumlu [37] have also verified the superior thermal efficiency and long-term stability of silver-water nanofluids in thermosyphon heat pipes in evacuated tube solar collectors. They found that silver nano-particles enhance solar collector efficiency from $20.7 \%$ and $40 \%$ compared with the pure water. In the simulations conducted therefore we first elaborate on silver-water nanofluid performance and thereafter compare with an alternative metallic nanofluid, namely Titanium oxide-water.

It is evident that the Rosseland flux model (Fig 5a) predicts a temperature field (Figure 5a) significantly different from that obtained without radiation (Fig. 5b). For the low optical thickness in this problem, the temperature field predicted by the Rosseland model is not physically realistic. The P-1 differential radiative model (Fig. 5c) produces a more homogenous thermal effect adjacent to the hot wall and enables radiative flux to penetrate more evenly through the nanofluid enclosure, whereas the Rosseland model predicts a biased temperature enhancement only in the top left corner. The isotherms are weakly distorted with the Rosseland 
model whereas they are substantially morphed with the P1 flux model and heat permeates the enclosure more strongly in the upper zone with cooler fluid in the lower zone. There however remains a dominant thermal zone associated with radiative flux in the vicinity of the left (heated) solar receiving wall. Furthermore, the hotter isotherms are more widely dispersed for the P1 flux model case which clearly simulates the absorption of radiation more accurately than the Rosseland flux model. With no radiation present no tangible thermal penetration is achieved and there is no distortion in isotherms. Radiative flux therefore exerts a considerable role and the simulations since it augments the thermal diffusivity of the working fluid. Apparently solar collector models including this mode of heat transfer produce more realistic representations of solar heat flux absorption.

Figs 6 a-b visualize the streamline (velocity contour) plots obtained again for Silver-water nanofluid with low volume fraction $=0.01$ (1\% doping), for a square enclosure $(A R=L / B=1)$ with Rayleigh number, $R a=10^{4}$ and radiative absorption coefficient of 0.2 . Although a single cell is computed for both cases, significantly higher magnitudes are observed with the P1 flux model (Fig 6a) compared with the Rosseland model (Fig 6b). An almost stagnant zone arises at the centre of the enclosure where vorticity effects are minimized. The streamlines are also in closer proximity especially in the periphery of the enclosure where higher temperature is generated for the P1 model case (Fig 6a). In the vicinity of the enclosure walls there is elevated mobility of silver nanoparticles and a reduction in viscosity. Acceleration is therefore computed in this region and this concurs with the findings of Qi et al. [31] although they considered Gallium as the base fluid. Since the velocity field is coupled to the temperature field in natural convection, it is influenced by radiative transfer flux. The P1 model yields the correct velocity profiles since the radiation source in the energy equation, which is proportional to the absorption coefficient, is small. The Rosseland model uses an effective conductivity to account 
for radiation, and yields the wrong temperature field, which in turn results in markedly lower accuracy in the computation of the velocity field and streamline distribution.

Figs 7a-b depict the isotherm plots for silver-water nanofluid with stronger natural convection i.e. thermal buoyancy $\left(R a=10^{5}\right)$ with a much higher nano-particle volume fraction $(\Phi=0.04)$ for the P1 flux case and no radiative heat transfer cases, respectively. Compared with figs $5 \mathrm{~b}$ (non-radiative) and 5c (P1 flux case) a significant modification is only observed with the P1 flux case (Fig 7a). The hotter fluid zone is found to push further from the hot wall and occupies a greater proportion of the enclosure. The colder zone which occupies the lower wall is largely eliminated and the lower right corner of the enclosure features a much-contracted cold zone. The enhanced thermal buoyancy coupled with the four hundred percent increase in silver nanoparticles occupying the cavity contribute strongly to encouraging thermal diffusion and transporting heat more effectively throughout the enclosure. Thermal conductivity of the nanofluid increases with increase in volume concentration. There is also a reduction in thermal boundary layer thickness at the walls and colder nanofluid is confined to the right wall with a narrower (constricted) zone in the lower half space of the enclosure. Higher doping of silver nano-particles successfully improves the circulation of heat in the enclosure and is assisted by thermal buoyancy. There is a weak transition in the isothermal profiles for the non-radiative case (Fig 7b) compared with earlier case (Fig 5b) - isotherms are skewed towards the right wall- however there is no tangible change in temperatures with yellow-green zones persisting in the vicinity of the hot wall, and becoming progressively cooler (green) towards the central area and eventually cooling further (dark green zones) near the cold right wall. The absence of radiative heat transfer therefore has a critical influence on the impact of higher thermal buoyancy (Rayleigh number) and increased silver nano-particle doping. Inclusion of radiative heat transfer is essential since the entire energy in the enclosure is received from the exterior by radiation, as noted by Gomez et al. [38]. However, it is further of note that radiative heat 
transfer modelling could be improved especially for directional accuracy and high participating media with alternate models such as the Chandrasekhar discrete ordinates model, as elaborated by Howell et al. [39]. Also, more advanced radiative models may provide deeper insight into thermophysical behaviour of silver nanoparticles, as described by Maddah et al. [40]. Figs 7cd illustrate the streamline plots again for silver-water nanofluid with stronger thermal buoyancy $\left(R a=10^{5}\right)$ with a higher nano-particle volume fraction $(\Phi=0.04)$ for the P1 flux case and no radiative heat transfer cases, respectively. Compared with figs $5 \mathrm{~b}$ (non-radiative) and 5c (P1 flux case) a significant modification is only observed with the P1 flux case (Fig 7c). The central cell is warped into a peanut-shaped zone and there is a narrowing in streamlines especially at the periphery of the enclosure. Significantly higher magnitudes are computed compared with the lower Rayleigh number and lower volume fraction case shown earlier (Fig 5c). The central zone is expanded laterally but constricted vertically with greater intensity around the periphery of the distorted inner cell. Flow acceleration is therefore generated for the P1 flux model. Although no significant modification is observed in the topology of the streamlines in the nonradiative case (Fig 7d) compared with Fig 5b, there is a notable increase in streamline magnitudes. Again, therefore the nanofluid circulation is accelerated albeit with no distortion of the inner cell.

Figs 8a-d present the isotherm plots and streamline plots for silver-water nanofluid with even stronger natural convection i.e. thermal buoyancy $\left(R a=10^{6}\right)$ again with high nano-particle volume fraction $(\Phi=0.04)$ for the P1 flux case and no radiative heat transfer cases, respectively. Comparing Fig 8a with Fig 7a, there is an even deeper penetration of hot nanofluid towards the cold (right) wall. Higher temperature contours dominate the upper half space of the enclosure with the colder zone isolated in the lower half space and this applies across the width of the enclosure. The maximum temperature zone is extended in the upper left of the enclosure and orange zones protrude further into the enclosure. Evidently higher Rayleigh 
number therefore mobilizes strong thermal convection currents in the enclosure and allows enhanced transfer of thermal energy across the enclosure. The cold blue narrow zone immediately adjacent to the right cold wall is also narrowed noticeably and warmer nanofluid (green contours) penetrates deeper approaching more closely to the cold wall. Fig 8b shows that the isotherms are further distorted with higher Rayleigh number although yellow and green (warm) zones remain without the hotter zones extending from the left wall. The absence of radiation therefore again leads to inadequate capturing of the modified thermal distribution. Fig $8 \mathrm{c}$ illustrates that yet greater distortion of the cellular structure in the enclosure is induced with greater Rayleigh number. The central zone is further modified into an asymmetric topology and extends further towards the left and right walls. Much higher velocities are computed in Fig. 8c compared with Fig. $7 \mathrm{c}$ since the buoyancy effect is ten times stronger $(R a$ is $10^{5}$ in Fig 7c). The peanut shaped central cell in Fig. 7c is distinctly morphed in Fig 8c. Streamlines are constricted again near all the edges of the enclosure indicating intensification in the flow. The trend is that the flow is tending towards a bifurcating cellular structure where multiple zones are synthesized in the central area of the enclosure. Instability can be induced thereafter, and attention is therefore limited in the simulations to $R a=10^{6}$ as the maximum Rayleigh number studied. Fig $8 \mathrm{~d}$ shows that the streamline distributions are skewed slightly towards the upper right of the enclosure with $R a=10^{6}$ compared with Fig $7 \mathrm{~d}\left(R a=10^{5}\right)$. The central zone is also somewhat expanded compared with higher Rayleigh number i.e. stronger natural convection. However, there is a distinct deceleration in the flow i.e. streamline magnitudes are reduced with greater Rayleigh number for the non-radiative case.

Fig. 9 depicts the influence of Rayleigh number on Nusselt number along the heated (left) wall for silver water nanofluid at $4 \%$ volume fraction, based on Eqn. (10), once again for a square enclosure (aspect ratio, $A R=1$ ). These profiles correspond only to the P1 radiative flux model. An increase in Rayleigh number clearly elevates strongly the local Nusselt number magnitudes. 
There is also a considerable elevation in Nusselt number as we progress from the base of the enclosure $(y=0)$ to the top of the enclosure $(y=1)$. Minimal Nusselt number is consistently computed at the base of the left wall and maximum Nusselt number at the top of the wall, irrespective of the Rayleigh number. Increasing thermal buoyancy therefore exerts a significant influence on wall heat transfer characteristics at the solar flux loaded boundary (hot left wall).

Figs 10-12 illustrate the relative performance, in terms of Nusselt number achieved with silverwater nanofluid and Titanium oxide-water nanofluid, again with the P1 flux radiative model and $4 \%$ volume fraction. Titanium oxide has a significantly lower thermal conductivity than silver and the latter is also more stable (longer shelf life) when suspended in base water [38]. Silver has superior optical (reflective) properties whereas titanium has anti-corrosion properties. However, Titanium is less than half the density of silver and therefore less liable to settle towards the base of the solar collector over longer periods of use. All metallic nanoparticles tend to agglomerate or aggregate due to the van der Waals forces, which can bind several particles together into a lump of particles. As a result of gravitational effects, these denser metallic nano-particles will conglomerate at the base of the container (solar collector). The overall nanofluid thermal conductivity will therefore be modified since better performance requires uniform distribution of nano-particles throughout the base fluid. While silver water nanofluid will have a significantly greater overall thermal conductivity than titanium oxide water nanofluid, the latter will still have a much greater thermal conductivity compared to water. Fedele et al. [41] and Saleh et al. [42] have further elaborated that the interfacial layer of water molecules engulfing the metallic nanoparticles enhances thermal conductivity since the water molecules surrounding the nanoparticles exhibit greater order and uniform distribution compared with pure water molecules further from the nano-particles. Very close magnitudes are computed for the Nusselt numbers with both silver and titanium oxide nanofluids at any given Rayleigh number, although the magnitudes are marginally higher for 
titanium oxide. Initially all profiles descend from the hot wall and thereafter rise steadily with distance along the wall culminating in the maximum Nusselt number near the top of the left hot wall. With increasing Rayleigh number from $10^{4}$ (fig. 10) to $10^{5}$ (fig.11) to $10^{6}$ (fig. 12) there is a progressive increase in Nusselt number indicating greater heat transfer to the enclosure nanofluid. Other mechanisms may also contribute in addition to thermal buoyancy, such as thermophoresis and Brownian motion. However, these cannot be simulated with the Tiwari-Das nanofluid model and require alternative nanoscale mathematical models [43, 44] which are not available in ANSYS FLUENT software.

Figs 13-22 illustrate the impact of aspect ratio on isotherms and streamline plots. In these figures we consider Titanium oxide-water nanofluid with the P1 radiative flux model, volume fraction of $\Phi=0.04$, and $R a=10^{5}$. The solar heat flux is maintained at the same value on the left hot wall. Five different aspect ratios (AR) are considered: 4 (very tall enclosure), 2 (tall enclosure), 4/3 (an enclosure which is slightly taller than wide), 1 (square), to 0.5 (shallow enclosure). Comparing isotherms first we consider the variation in Fig. 13 ( $\mathrm{AR}=4)$, Fig. $15(\mathrm{AR}=2)$, Fig. $17(\mathrm{AR}=4 / 3)$, Fig. $19(\mathrm{AR}=1)$ and finally Fig. $21(A R=0.5)$. Significant alteration in the temperature contours is instigated with a progressively decreasing aspect ratio. With decreasing aspect ratio $(A R=$ ratio of height of enclosure to width of enclosure) hotter nanofluid begins to penetrate deeper into the upper half space. The cold zone (blue contours) adjacent to the right wall becomes increasingly localized in the lower half space of the enclosure. This process is accentuated as we reduce the AR from 4.3 to 1 and then eventually dominates with a shallow enclosure yellow and green contours occupying most of the enclosure space indicating enhanced thermal diffusion and more homogenous heat distribution throughout the collector geometry. Lower aspect ratio therefore encourages the synthesis of dual thermal zones at the upper and lower zones of the enclosure. Overall the isotherms are compressed towards the hot wall and the cold ceiling and most of the enclosure is occupied by warmer fluid at higher aspect ratios. Due to this effect, the single cell 
is expanded in both vertical and horizontal directions at higher aspect ratio with lesser distortion in the flow. This expansion results in boundary layer formation and is opposed at lower aspect ratios. The colder zone morphs from a blunt topology into a sharper bullet-shaped profile with smaller aspect ratio. Similar observations have been reported by Sheikhzadeh and Nikfar [45]. Comparing streamline plots (based on stream function) we study the variation in Fig. $14(\mathrm{AR}=4)$, Fig. $16(\mathrm{AR}=2)$, Fig. $18(\mathrm{AR}=4 / 3)$, Fig. $20(\mathrm{AR}=1)$ and finally Fig. 22 $(A R=0.5)$. Significant alteration in the temperature contours is instigated with a progressively decreasing aspect ratio. For aspect ratio greater than unity (Figs 14, 16 and 18) there is a distinct singular cell structure to the enclosure circulation. The structure is elongated in the vertical direction in Figs. 14 and 16 but disperses more laterally in Fig 18. A significant deceleration in the flow accompanies a decrease in aspect ratio from 4 to 2 i.e. lower magnitudes of stream function are computed. However, this trend is reversed with subsequent decrease in aspect ratio to $4 / 3$ for which acceleration is computed and this pattern continues with even further decrease in aspect ratio to unity and finally to 0.5 (Fig 22). The singular cell structure is retained however only down to an aspect ratio of $4 / 3$ and there is an increasing skewness in distributions towards the upper right corner of the cavity. At $A R=1$ (Fig. 20) a dual structure begins to emerge in the centre of the enclosure. At higher aspect ratio, the streamline distributions are more symmetrical whereas for $\mathrm{AR}=1$ and more so for $\mathrm{AR}=0.5$ (Fig. 22) a dis-symmetry is observed and a skewness emerges in the circulation which is biased towards the opposite wall i.e. the left hot wall of the solar enclosure. Vortex structure is therefore clearly influenced by aspect ratio. The central cell zone becomes increasingly elongated and distorted for $\mathrm{AR}=0.5$.

Fig. 23 shows the Nusselt number distribution along the left hot wall for Titanium oxide-water nanofluid with the P1 radiative flux model, volume fraction of $\Phi=0.04$, and $R a=10^{5}$. Nusselt number at the left hot wall is maximized at low aspect ratio $(\mathrm{AR}=0.5)$ and minimized at high aspect ratio $(A R=4)$ indicating that shorter and wider solar enclosures achieve significantly 
better heat transfer rates than taller and narrower enclosures. At highest aspect ratio $(\mathrm{AR}=4)$ Nusselt number remains invariant from the base of the hot wall for most of the length and is only increased marginally in the vicinity of the uppermost region along the wall. However, for lower aspect ratios Nusselt number generally grows consistently with progression along the heated wall from the base to the upper end. Generally, titanium oxide-water nanofluid produces quite good thermal enhancement compared with pure water.

\section{CONCLUSIONS}

Computational simulations of steady-state nanofluid natural convection with thermal radiation in a two-dimensional solar collector enclosure have been presented. ANSYS FLUENT finite volume code (version 19.1) has been deployed. The Tiwari-Das volume fraction nanofluid model is used and three different nanoparticles are studied (Copper $(\mathrm{Cu})$, Silver $(\mathrm{Ag})$ and Titanium Oxide $\left(\mathrm{TiO}_{2}\right)$ ) with water as the base fluid. The Trauggot P1 flux and Rosseland diffusion models have been utilized to analyse radiative heat transfer which is imposed as solar thermal radiative flux at the hot left wall of the enclosure. Mesh-independence tests have been included. ANSYS isotherm and streamline computations have been validated with published studies from the literature for the copper-water nanofluid case. Extensive results have been presented for temperature contours, streamlines and Nusselt number distribution along the heated wall for both silver-water and titanium oxide-water nanofluids. The present investigation has shown that:

i)P1 model more accurately predicts the actual influence of solar radiative flux on thermal fluid behaviour compared with Rosseland radiative model and accurately reproduces the penetration of heat deeper into the enclosure.

ii)With increasing Rayleigh number (natural convection i.e. buoyancy effect), significant modification in the thermal flow characteristics is induced with emergence of a dual structure 
to the circulation. Temperatures are generally enhanced with greater Rayleigh number for the both the silver-water nanofluid case and titanium oxide water nanofluid case, although greater temperatures are computed in the former and slightly higher Nusselt numbers in the latter.

iii)With decreasing aspect ratio (wider base relative to height of the solar collector geometry) higher temperatures are generated in the enclosure and hotter titanium oxide water nanofluid reaches deeper into the enclosure space. At lower aspect ratio (less than or equal to unity) dual thermal zones are generated in the upper and lower zones of the enclosure.

iv) A substantial deceleration in the titanium oxide water nanofluid flow is induced initially with a decrease in aspect ratio from 4 to 2 ; however, this pattern is reversed with subsequent decrease in aspect ratio (aspect ratio of 4/3, 1 and 0.5) and flow is accelerated. The singular symmetric cell structure observed at higher aspect ratio is modified into a non-symmetric laterally elongated structure at low aspect ratios.

v) With increasing nano-particle volume fraction of silver nano-particles, heat circulation in the enclosure is encouraged, thermal conductivity is enhanced, and this is also assisted at greater Rayleigh numbers.

vi) Higher Rayleigh number and nano-particle fraction also causes the central cell to be warped in the streamline distribution and accelerates the flow in the enclosure.

CFD has been shown to be a useful tool in studying metallic nanofluid-solar collector performance. The present simulations provide a solid benchmark for experimental studies and may also be extended to consider other metallic nanoparticles (gold, zinc etc), base fluids (e.g. ethylene glycol) [45, 46] and, also transient effects. These aspects are currently under consideration. 


\section{CONFLICT OF INTEREST}

On behalf of all authors, the corresponding author states that there is no conflict of interest.

\section{REFERENCES}

[1] Choi, S., Enhancing thermal conductivity of fluids with nanoparticles, Proceedings of the ASME International Mechanical Engineering Congress and Exposition, San Francisco, CA. (1995).

[2] Das, S. K., Choi, S. U. S., Yu, W., and Pradet, T., Nanofluids: Science and Technology, Wiley, Hoboken, NJ. (2007).

[3] Oliveira, G.A and Bandarra Filho, E.P, Nanofluid as a coolant in automotive radiators, $10^{\text {th }}$ International Conference on Heat Transfer, Fluid Mechanics and Thermodynamics, Orlando, Florida, $14-26$ July (2014).

[4] O. Anwar Bég, D.E. Sanchez Espinoza, Ali Kadir, M. Shamshuddin, A. Sohail Experimental study of improved rheology and lubricity of drilling fluids enhanced with nanoparticles, Applied Nanoscience, 8 (5), 1069-1090 (2018).

[5] Zhao, N., Wen, X., and Li, S., An evaluation of the application of nanofluids in intercooled cycle marine gas turbine intercooler, ASME J. Eng. Gas Turbines Power, 138 (1), (2015).

[6] Salata, O.V., Applications of nanoparticles in biology and medicine, J. Nanobiotechnology, 2, 3 (2004). doil:0.1186/1477-3155-2-3

[7] Ali, N., Zaman, A., Sajid, M., Anwar Bég, O., Shamshuddin, MD. and Kadir, A., Computational study of unsteady non-Newtonian blood flow containing nano-particles in a tapered overlapping stenosed artery with heat and mass transfer, NanoScience and Technology: An International Journal, 9(3),247-282, (2018). 
[8] Rafiqul Islam, M., Shabani, B. and Rosengarten, G., Nanofluids to improve the performance of PEM fuel cell cooling systems: A theoretical approach, Applied Energy, 178, 660-671 (2016).

[9] Okonkwo, E. C., Abid, E., Ratlamwala, T.A.H., Abbasoglu, S. and Dagbasi, M., optimal analysis of entropy generation and heat transfer in parabolic trough collector using greensynthesized $\mathrm{TiO}_{2} /$ Water Nanofluids, ASME J. Sol. Energy Eng., 141(3) (2018).

[10] Prakash, J., Siva, E.P., Tripathi, D., Kuharat, S. and Anwar Bég, O., Peristaltic pumping of magnetic nanofluids with thermal radiation and temperature-dependent viscosity effects: modelling a solar magneto-biomimetic nanopump, Renewable Energy, (2018). doi.org/10.1016/j.renene.2018.08.096 0960-1481

[11] Moghadam, M.C., Edalatpour, M. and Solano, J.P., Numerical study on conjugated laminar mixed convection of alumina/water nanofluid flow, heat transfer, and entropy generation within a tube-on-sheet flat plate solar collector, ASME J. Sol. Energy Eng. 139(4), 694-722, (2017).doi: 10.1115/1.4036854

[12] Bait, O. and Si-Ameur, M., Enhanced heat and mass transfer in solar stills using nanofluids: A review, Solar Energy, 170, 694-722 (2018).

[13] Otanicar, T. P., Phelan, P. E., Prasher, R. S., Rosengarten, G. and Taylor, R. A. Nanofluidbased direct absorption solar collector, Journal of Renewable and Sustainable Energy 2, 2, 033102.1- 2, 033102.13 (2010).

[14] Karamia, M., Bozorgib, M., Delfanic, S. and Akhavan-Behabadib, M.A., Empirical correlations for heat transfer in a silver nanofluid-based direct absorption solar collector, Sustainable Energy Technologies and Assessments, 28, 14-21 (2018).

[15] Tyagi, H., Phelan, P. and Prasher, R., Predicted efficiency of a low-temperature nanofluidbased direct absorption solar collector, ASME J. Sol. Energy Eng, 131(4), 041004 (2009). 
[16] Gorji, T.B. and Ranjbar, A.A., Thermal and exergy optimization of a nanofluid-based direct absorption solar collector, Renewable Energy, 106, 274-287 (2017).

[14] Godson, L., Raja, B., Lal, D.M. and Wongwises, S., Enhancement of heat transfer using nanofluids an overview, Renew. Sustain. Energy Rev, 14, 629-641 (2010).

[15] Bozorgan, N. and Shafahi, M., Performance evaluation of nanofluids in solar energy: a review of the recent literature, Micro and Nano Systems Letters, 3, 5 (2015).

[16] Kosti, S, Das, M. K. and Saha, A. K., Buoyancy-driven flow and heat transfer in a nanofluid-filled enclosure, Nanomaterials and Energy, 2(4), 200-211 (2013).

[17] Ogut, E. B., Natural convection of water-based nanofluids in an inclined enclosure with a heat source. Int J Therm. Sci., 48, 2063-73 (2009).

[18] Arani, A. A. A., Ababaei, A, Sheikhzadeh, G. A. and Aghaei, A., Numerical simulation of double-diffusive mixed convection in an enclosure filled with nanofluid using Bejan's heat lines and mass lines, Alexandria Engineering Journal, 57 (3) 1287-1300 (2017).

[19] Yu, Q., Xu, H. and Liao, S., Analysis of mixed convection flow in an inclined lid-driven enclosure with Buongiorno's nanofluid model, International Journal of Heat and Mass Transfer, 126, 221-236, (2018).

[20] Ahmed, M. and Eslamian, M., Numerical simulation of natural convection of a nanofluid in an inclined heated enclosure using two-phase lattice Boltzmann method: accurate effects of thermophoresis and Brownian forces, Nanoscale Research Letters, 10: 296-307 (2015).

[21] Tiwari, R.K. and Das, M.K., Heat transfer augmentation in a two-sided lid-driven differentially heated square cavity utilizing nanofluids. Int J Heat Mass Transfer, 50, 20022018, (2007).

[22] Sheremet, M. A., Grosan, T. and Pop, I., Free convection in a square cavity filled with a porous medium saturated by nanofluid using Tiwari and Das' nanofluid model, Transport in Porous Media, 106(3) , 595-610, (2015). 
[23] Muthtamilselvan, M., Kandaswamy, P. and Lee, L., Heat transfer enhancement of copperwater nanofluids in a lid-driven enclosure, Commun. Nonlinear Sci. Numer. Simul., 15, 15011510, (2010).

[24] Sharaf, O. Z., Kyritsis, D. C., Al-Khateeb, A. N. and Abu-Nada, E., Effect of bottom surface optical boundary conditions on nanofluid-based DASC: Parametric study and optimization, Solar Energy, 164, 210-223, (2018).

[25] Mehmood, R., Tabassum, R., Kuharat, S., Anwar Bég, O. and Babaie, M., Thermal slip in oblique radiative nano-polymer gel transport with temperature-dependent viscosity: solar collector nanomaterial coating manufacturing simulation, Arabian J. Science and Engineering (2018). https://doi.org/10.1007/s13369-018-3599-y

[26] Sharaf, O. Z., Kyritsis, D. C. and Abu-Nada, E., Impact of nanofluids, radiation spectrum, and hydrodynamics on the performance of direct absorption solar collectors, Energy Conversion and Management, 156, 706-722, (2018).

[27] Lee, B. J., Park, K., Walsh, T. and Xu, L., Radiative heat transfer analysis in plasmonic nanofluids for direct solar thermal absorption, J. Sol. Energy Eng., 134(2), 021009 (2012).

[28] Bouhalleb, M. and Abbassi, H., Natural convection of nanofluids in enclosures with low aspect ratios, International Journal of Hydrogen Energy, 39(27), 15275-15286, (2014).

[29] Trodi, A. \& Benhamza, M. E. H., Particle shape and aspect ratio effect of Al2O3-water nanofluid on natural convective heat transfer enhancement in differentially heated square enclosures, Chemical Engineering Communications, 204 (2), 158-167 (2017).

[30] Wong, K., Bon, B. L., Vu, S. and Samedi, S., Study of nanofluid natural convection phenomena in rectangular enclosures, ASME International Mechanical Engineering Congress and Exposition, IMECE 2007 - Seattle, WA, United States, Nov 112007 -Nov 15 (2007). 
[31] Qi, C., Yang, L. and Wang, G., Numerical study on convective heat transfer enhancement in horizontal rectangle enclosures filled with Ag-Ga nanofluid, Nanoscale Research Letters, 12: 326 (2017).

[32] ANSYS FLUENT Theory Manual, ver 19.1, Swanson Analysis Systems, Pennsylvania, USA (2018).

[33] Atmaca, M.; Girgin, I.; Ezgi, C.: CFD modelling of a diesel evaporator used in cell systems. Int. J. Hydrogen Energy 41(14), 6004-6012 (2016).

[34] Abu-Nada, E. and Oztop, H.F., Effects of inclination angle on natural convection in enclosures filled with $\mathrm{Cu}$-water nanofluid, Int. J. Heat Fluid Flow, 30 (4), 669-678 (2009).

[35] R.Nasrin, S. Parvin and M.A. Alim, Heat transfer by nanofluids through a flat plate solar collector, Procedia Engineering, 90, 364-370 (2014).

[36] S. Roy et al., Heat transfer performance of silver/water nanofluid in a solar flat-plate collector, J. Thermal Engineering, 1 (2), 104-112 (2015).

[37] A. Ozsoy and V. Corumlu, Thermal performance of a thermosyphon heat pipe evacuated tube solar collector using silver-water nanofluid for commercial applications, Renewable Energy, 122, 26-34 (2018).

[38] M.A. Gómez et al., CFD simulation of a solar radiation absorber, International Journal of Heat and Mass Transfer, 57, 231-240 (2103).

[39] J.R. Howell, M. Pinar Menguc and R. Siegel, Thermal Radiation Heat Transfer, $6^{\mathrm{TH}}$ Edition, CRC Press, Florida, USA (2015).

[40] Maddah, H., Rezazadeh, M., Maghsoudi, M. and Nasiri Kokhdan, S., The effect of silver and aluminium oxide nanoparticles on thermophysical properties of nanofluids, $J$. Nanostructure in Chemistry, 3, 28 (2013). 
[41] Fedele, L.; Colla, L.; and Bobbo, S. Viscosity and thermal conductivity measurements of water-based nanofluids containing titanium oxide nanoparticles. International Journal of Refrigeration, 35(5), 1359-1366 (2012).

[42] Saleh, R.; Putra, N.; Wibowo, R.E.; Septiadi, W.N.; and Prakoso, S.P., Titanium dioxide nanofluids for heat transfer applications. Experimental Thermal and Fluid Science, 52 (Supplement C), 19-29 (2014).

[43] B. Vasu, Rama S. R. Gorla, O. Anwar Bég, P. V. S. N. Murthy, V. R. Prasad and A. Kadir, Unsteady flow of a nanofluid over a sphere with non-linear Boussinesq approximation, AIAA Journal of Thermophysics and Heat Transfer (2018). 13 pages. DOI: 10.2514/1.T5516

[44] J. Prakash, E.P. Siva, D Tripathi, S. Kuharat and O. Anwar Bég, Peristaltic pumping of magnetic nanofluids with thermal radiation and temperature-dependent viscosity effects: modelling a solar magneto-biomimetic nanopump, Renewable Energy (2018). 18 pages. doi.org/10.1016/j.renene.2018.08.096 0960-1481

[45] Sheikhzadeh, G. A. and Nikfar, M., Aspect ratio effects of an adiabatic rectangular obstacle on natural convection and entropy generation of a nanofluid in an enclosure, $J$. Mechanical Science and Technology, 27 (11), 3495-35, (2013).

[46] Notarianni, M., Notariannia, M., Vernona, K., Choua, A., Aljadab, M., Liua, J. and Motta, N., Plasmonic effect of gold nanoparticles in organic solar cells, Solar Energy, 106, 23-37, (2014). 


\section{FIGURES}

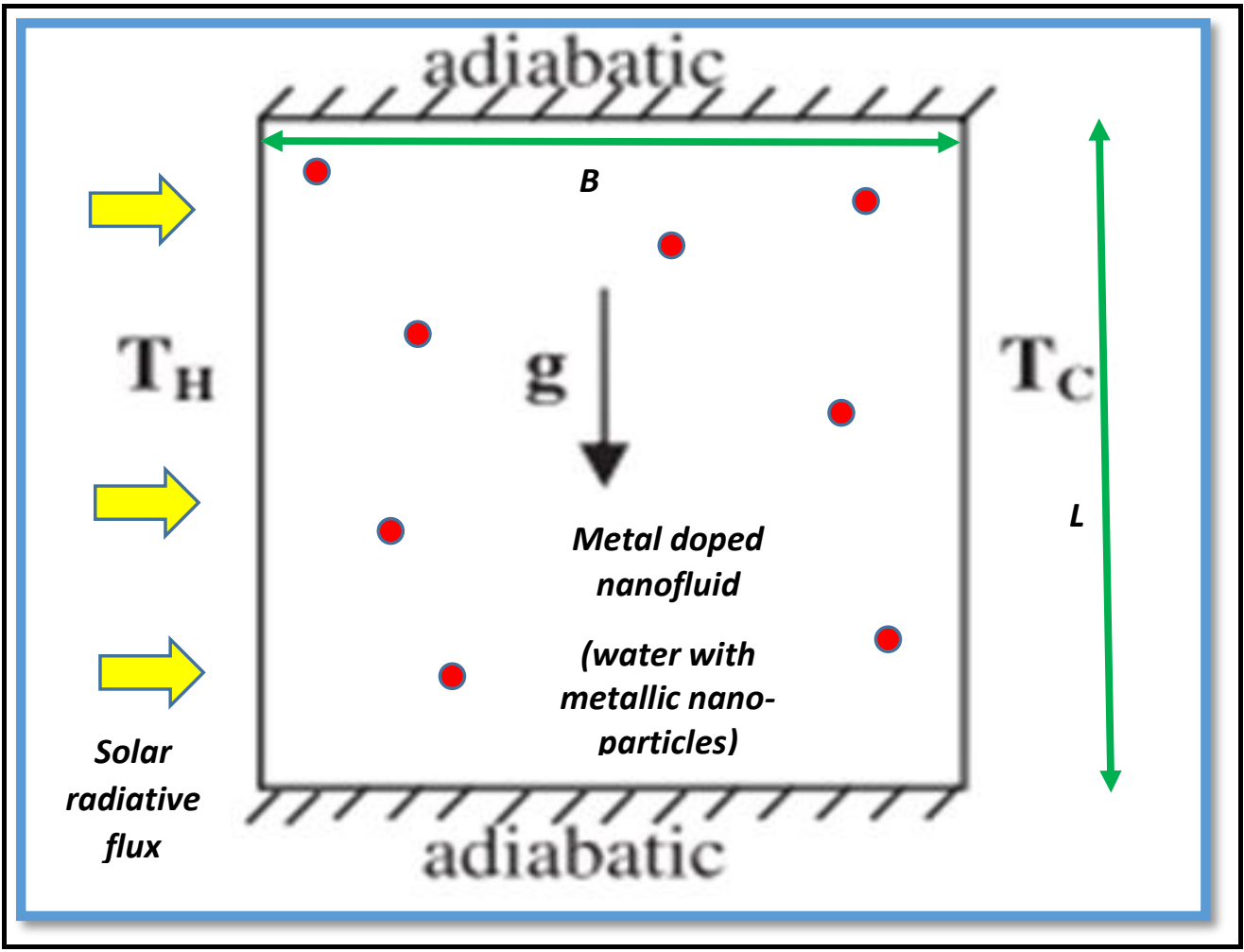

Fig. 1: Direct absorber solar nanofluid collector enclosure geometry

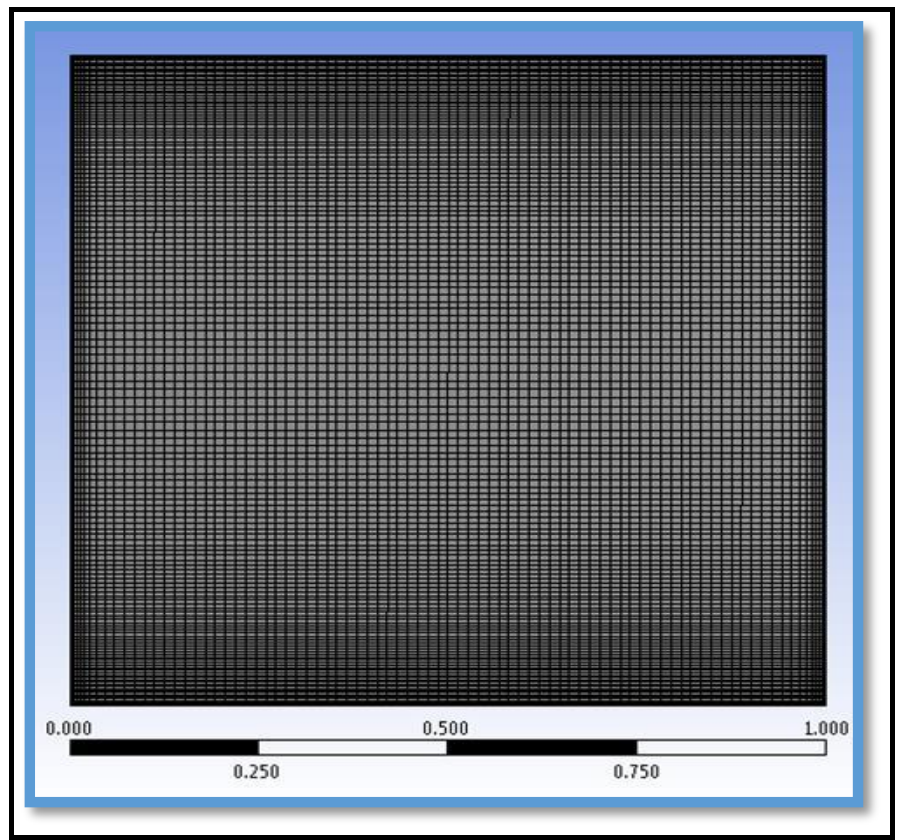

Fig 2. Mesh design for square enclosure case $(A R=1)$ 


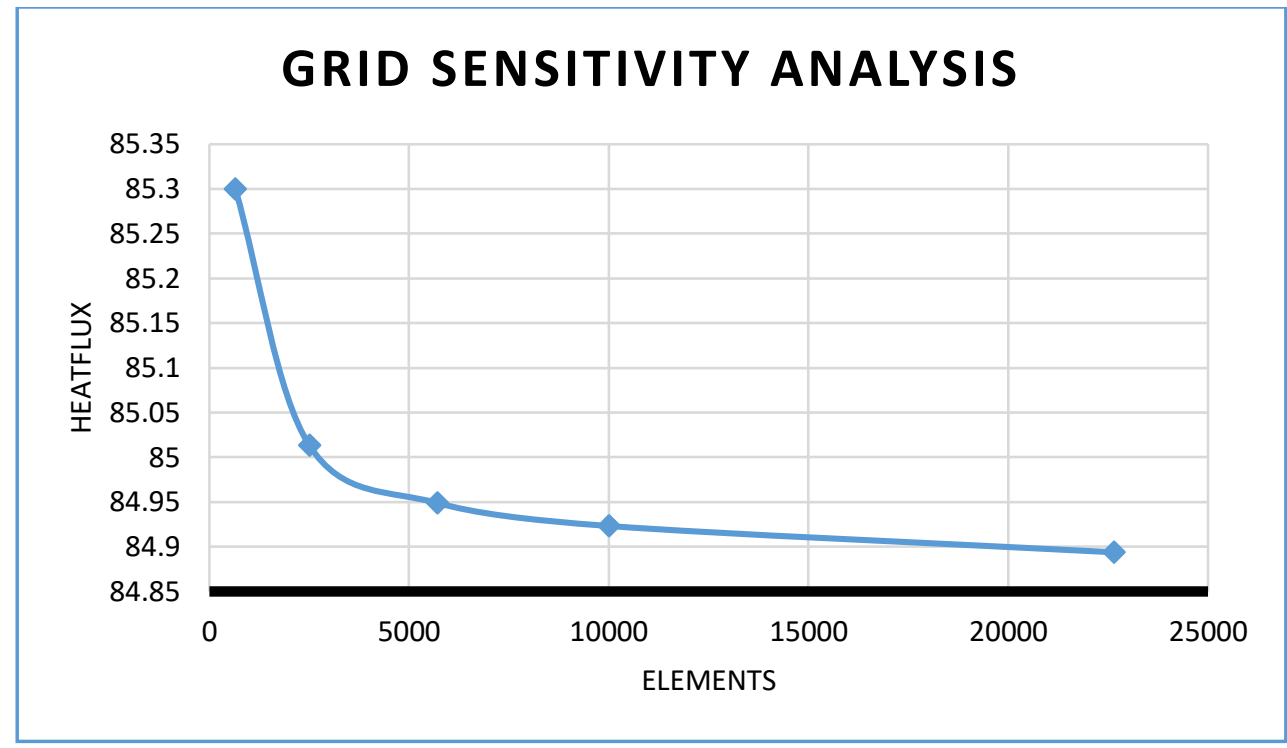

Fig 3: Mesh independence study for hot (left) wall heat flux 
a
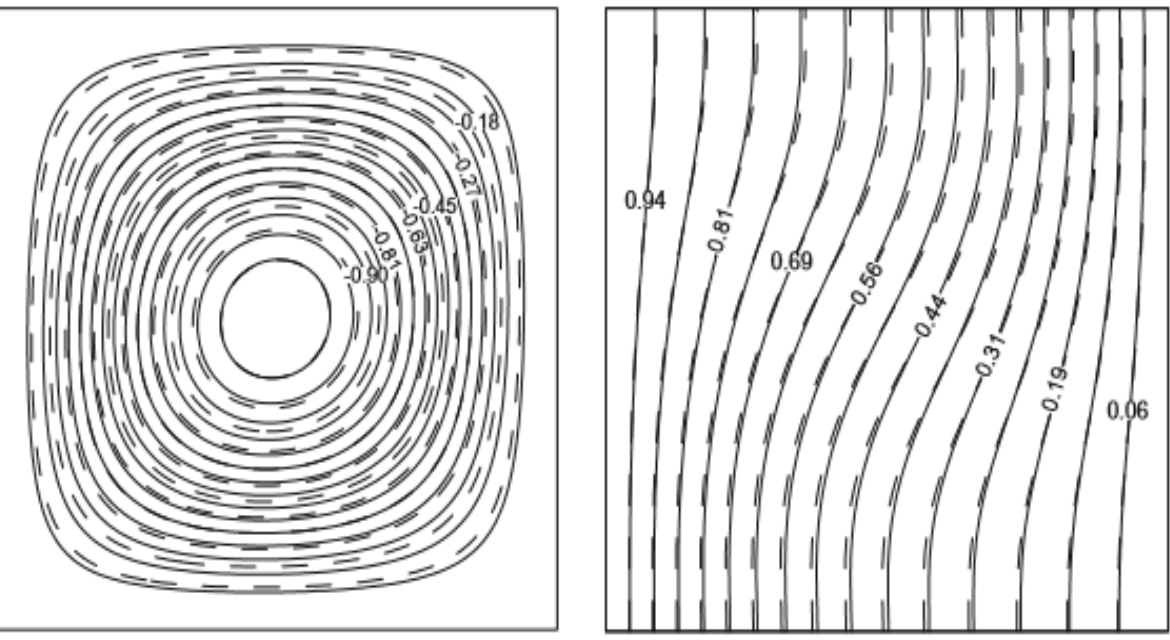

Fig A- finite volume results for Streamline and Isotherm plots for copper-water nanofluid, with a Rayleigh number of $10^{3}$, volume fraction of 0.01 (Abu-Nada, E., \& Oztop, H. 2009)

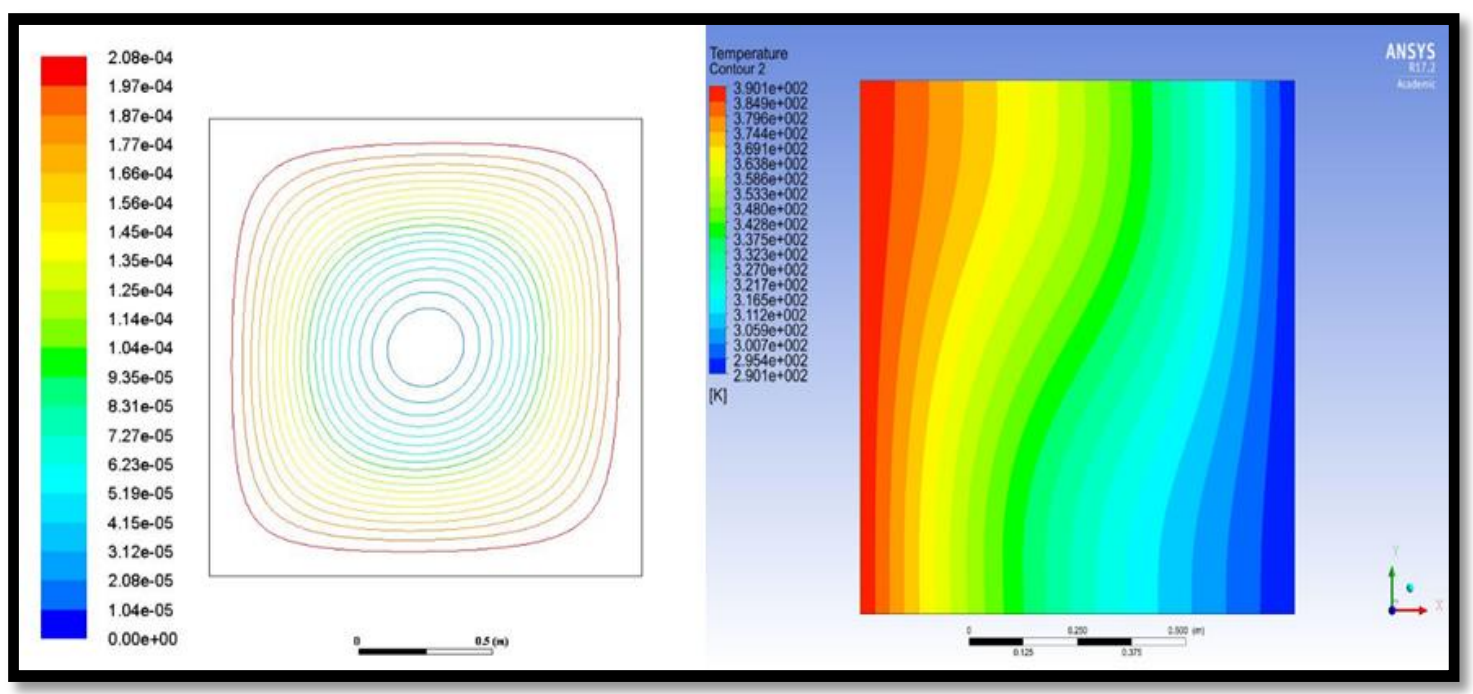

Fig B- ANSYS FLUENT Streamline and Isotherm plots for copper-water nanofluid, with a Rayleigh number of $10^{3}$, volume fraction of 0.01

Fig 4 A, B: Validation of ANSYS results with Abu-Nada and Oztop [33] 


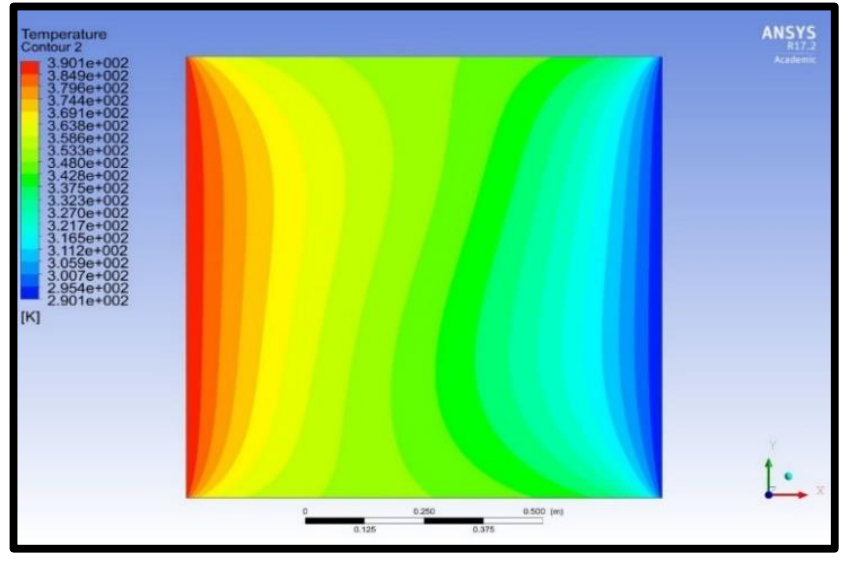

Fig 5a. Isotherms for silver-water nanofluid, $R a=10^{4}$, Rosseland flux model with $\Phi=0.01$.

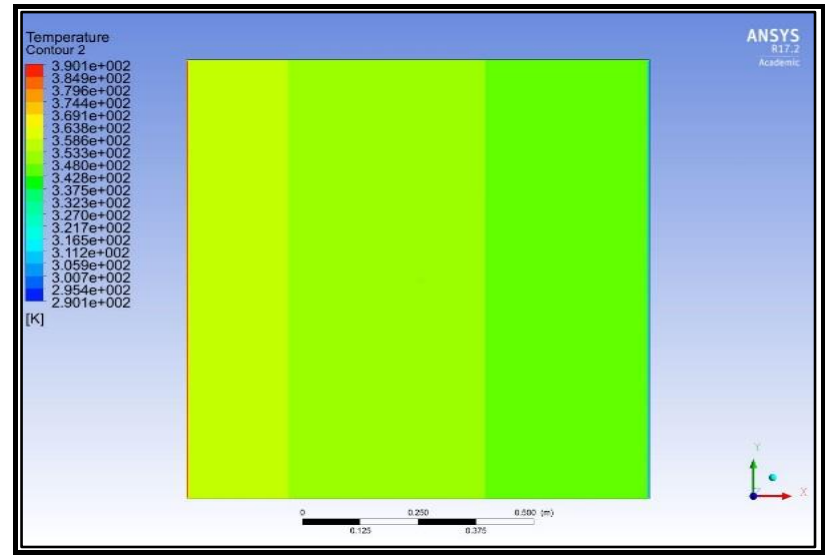

Fig 5b. Isotherms for silver-water nanofluid, $R a=10^{4}$, no radiative flux with $\Phi=0.01$.

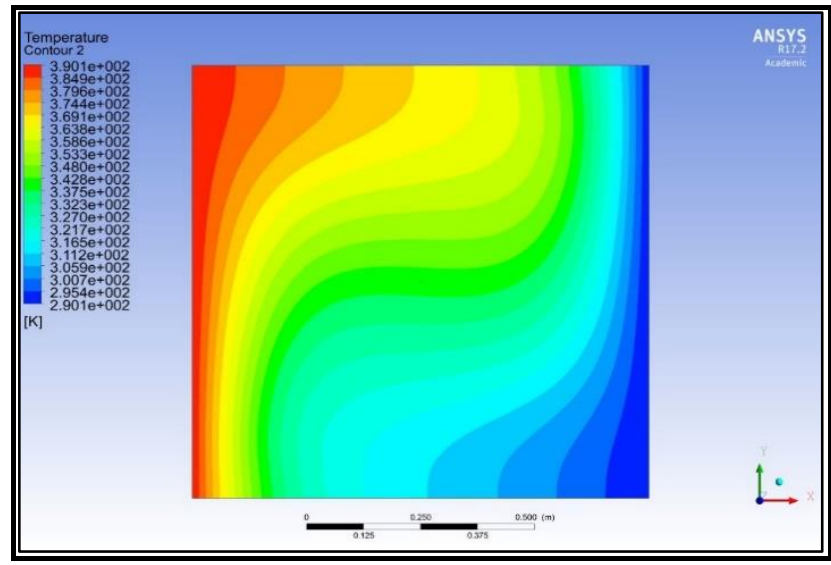

Fig 5c. Isotherms for silver-water nanofluid, $R a=10^{4}$, P1 radiative flux with $\Phi=0.01$. 


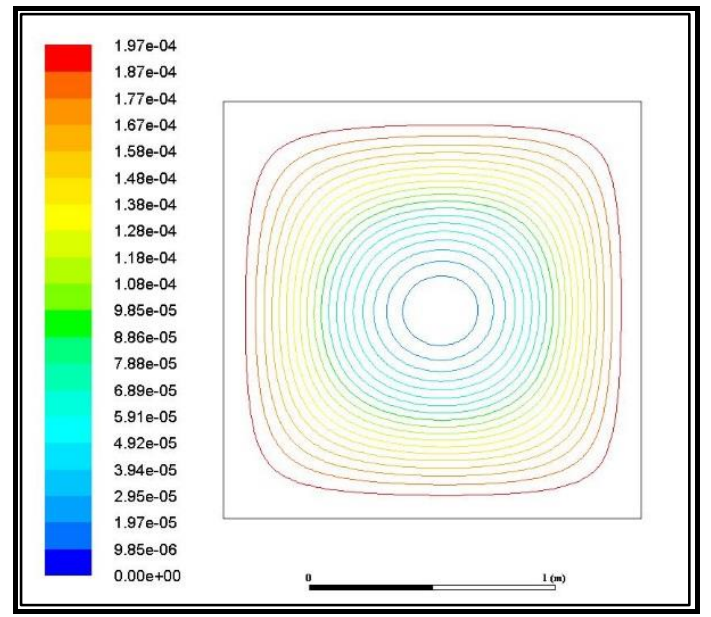

Fig 6a. Streamline distributions for silver-water nanofluid, $R a=10^{4}$, P1 flux model with $\Phi=0.01$.

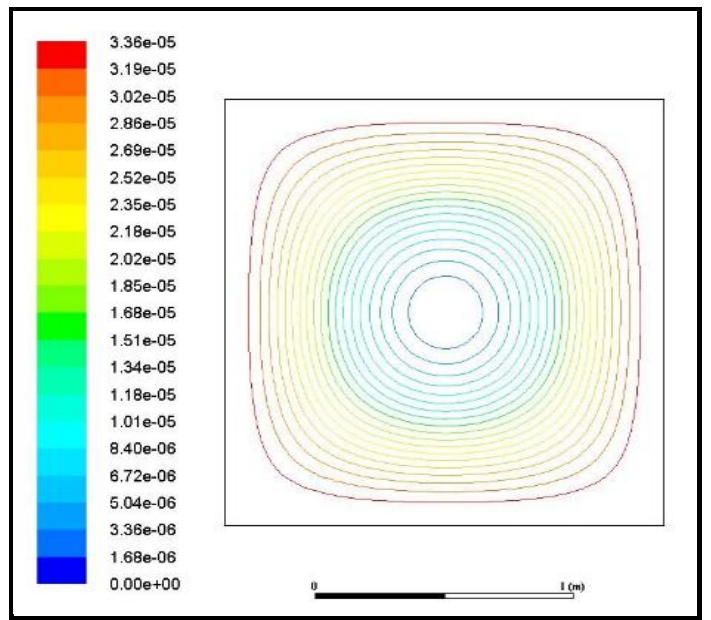

Fig 6b. Streamline distributions for silver-water nanofluid, $R a=10^{4}$, Rosseland flux with $\Phi=0.01$.

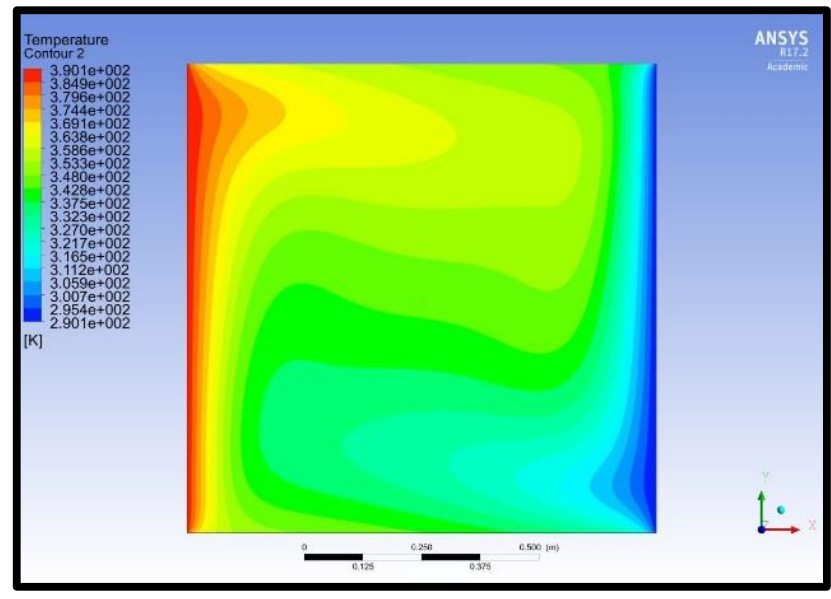

Fig 7a. Isotherms for silver-water nanofluid, $R a=10^{5}$, P1 radiative flux with $\Phi=0.04$. 


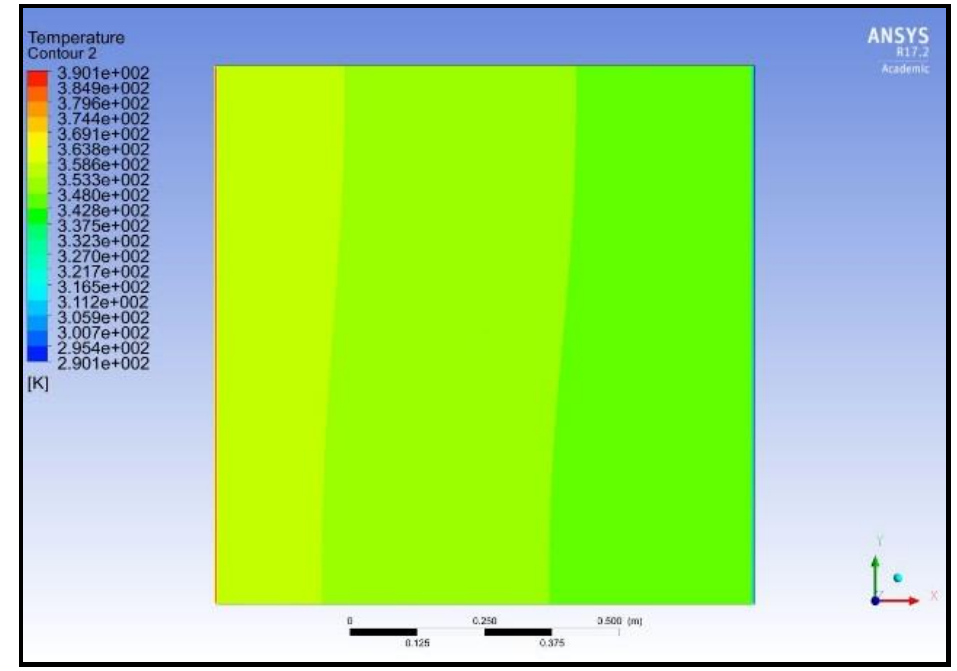

Fig 7b. Isotherms for silver-water nanofluid, $R a=10^{5}$, no radiative flux with $\Phi=0.04$.

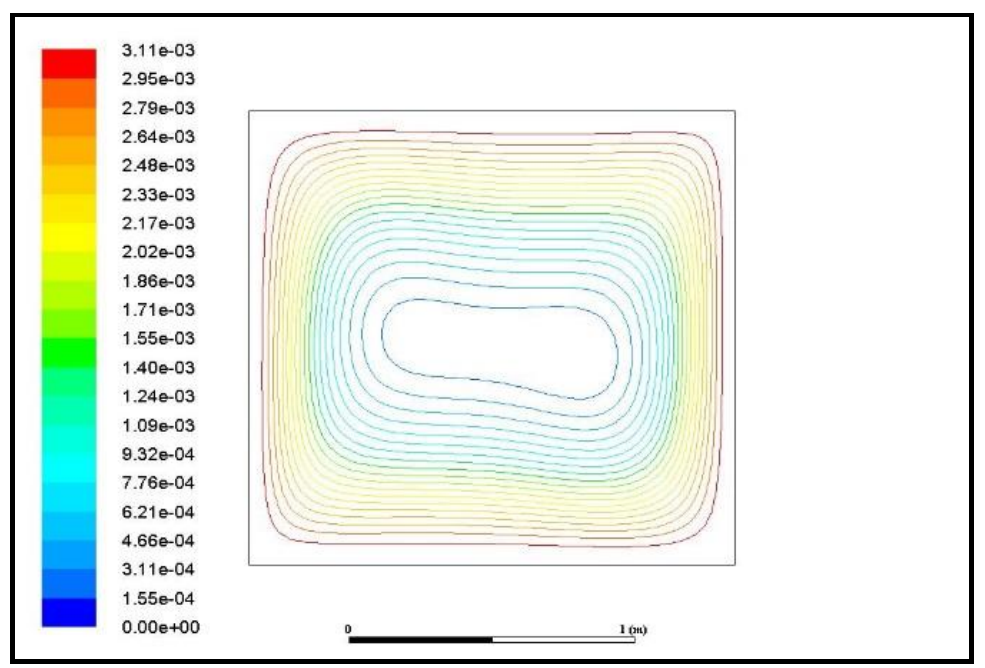

Fig 7c. Streamline distributions for silver-water nanofluid, $R a=10^{5}$, P1 radiative flux with $\Phi=0.04$.

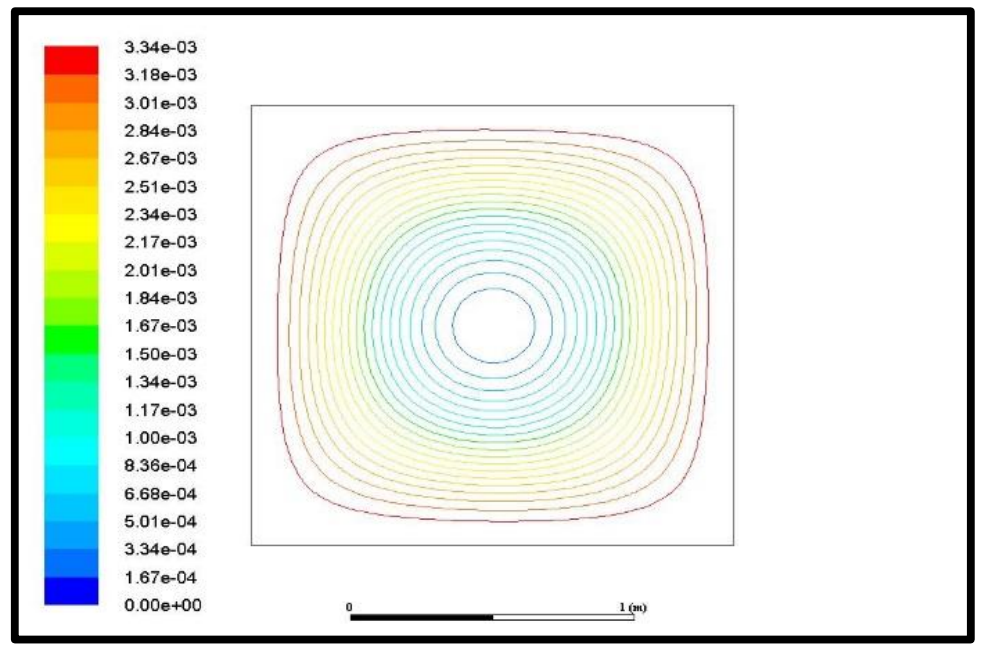

Fig 7d. Streamline distributions for silver-water nanofluid, $R a=10^{5}$, no radiative flux with $\Phi=0.04$. 


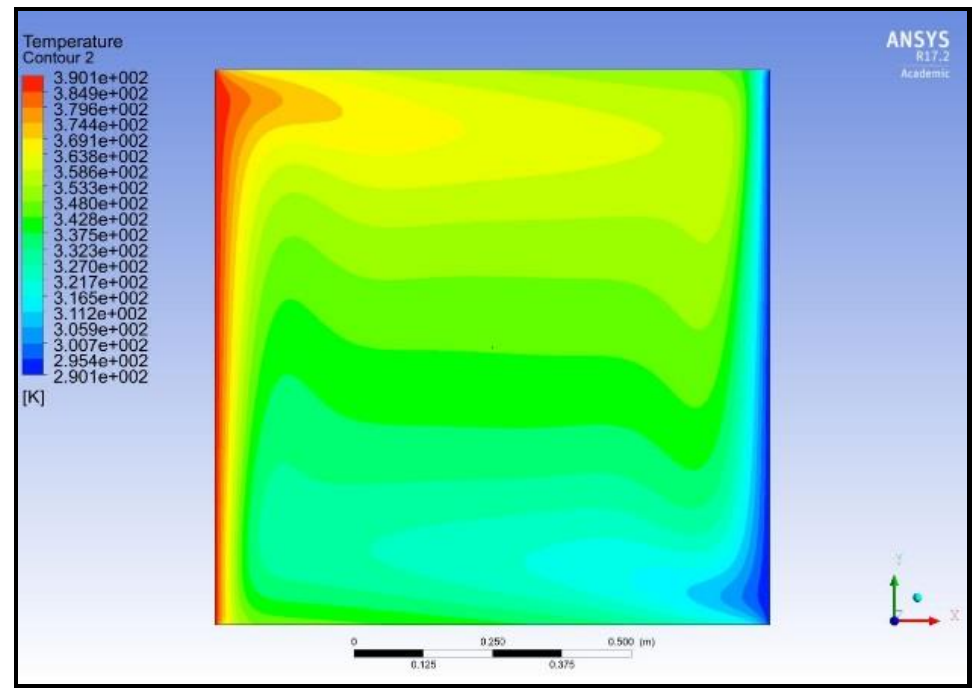

Fig 8a. Isotherms for silver-water nanofluid, $R a=10^{6}$, P1 radiative flux with $\Phi=0.04$.

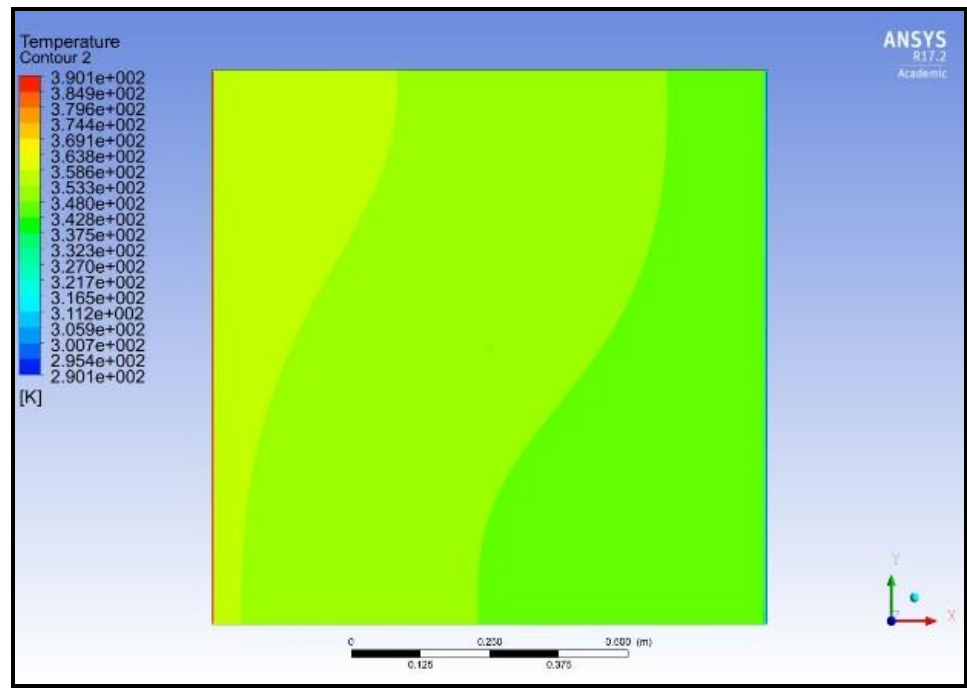

Fig 8b. Isotherms for silver-water nanofluid, $R a=10^{6}$, no radiative flux with $\Phi=0.04$.

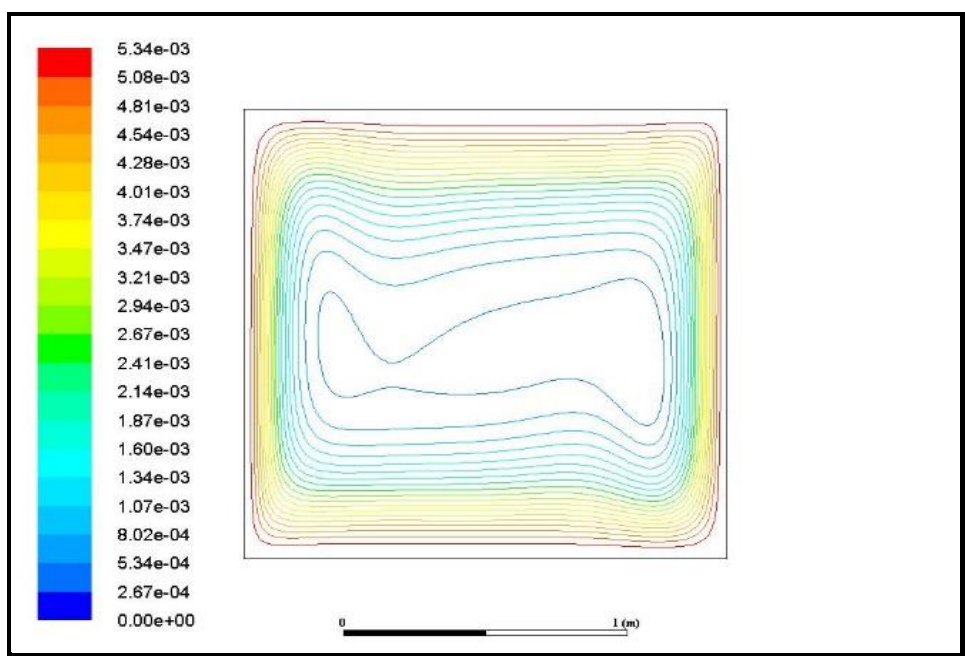

Fig 8c. Streamline distributions for silver-water nanofluid, $R a=10^{6}, P 1$ radiative flux with $\Phi=0.04$. 


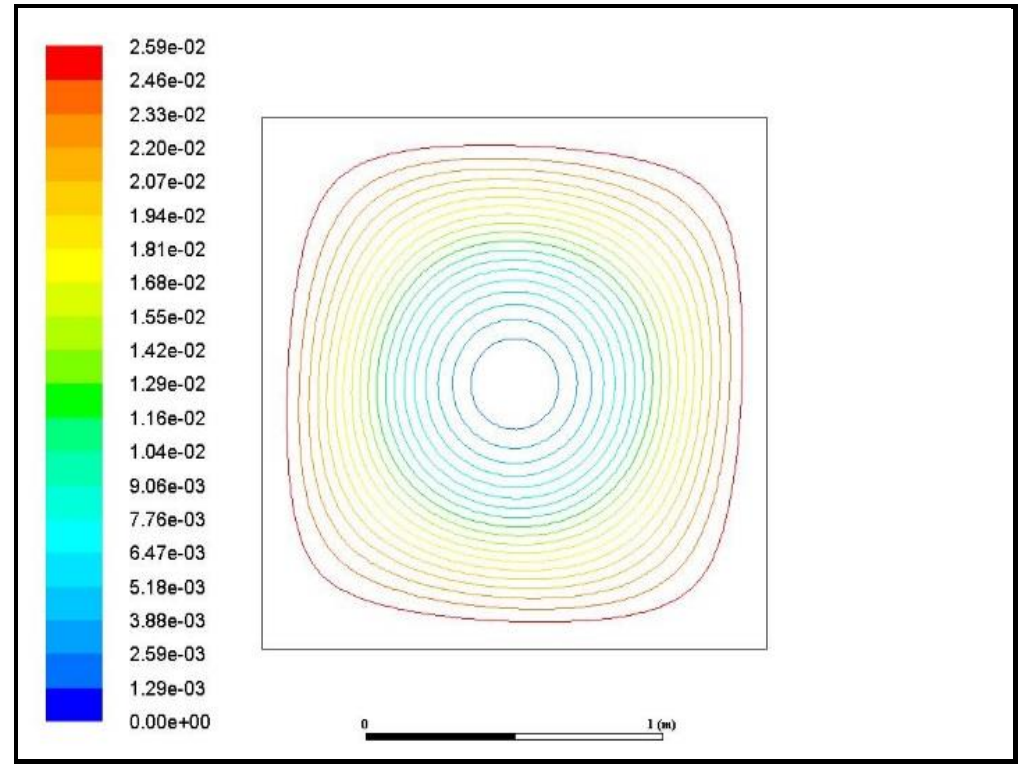

Fig 8d. Streamline distributions for silver-water nanofluid, $R a=10^{6}$, no radiative flux with $\Phi=0.04$.

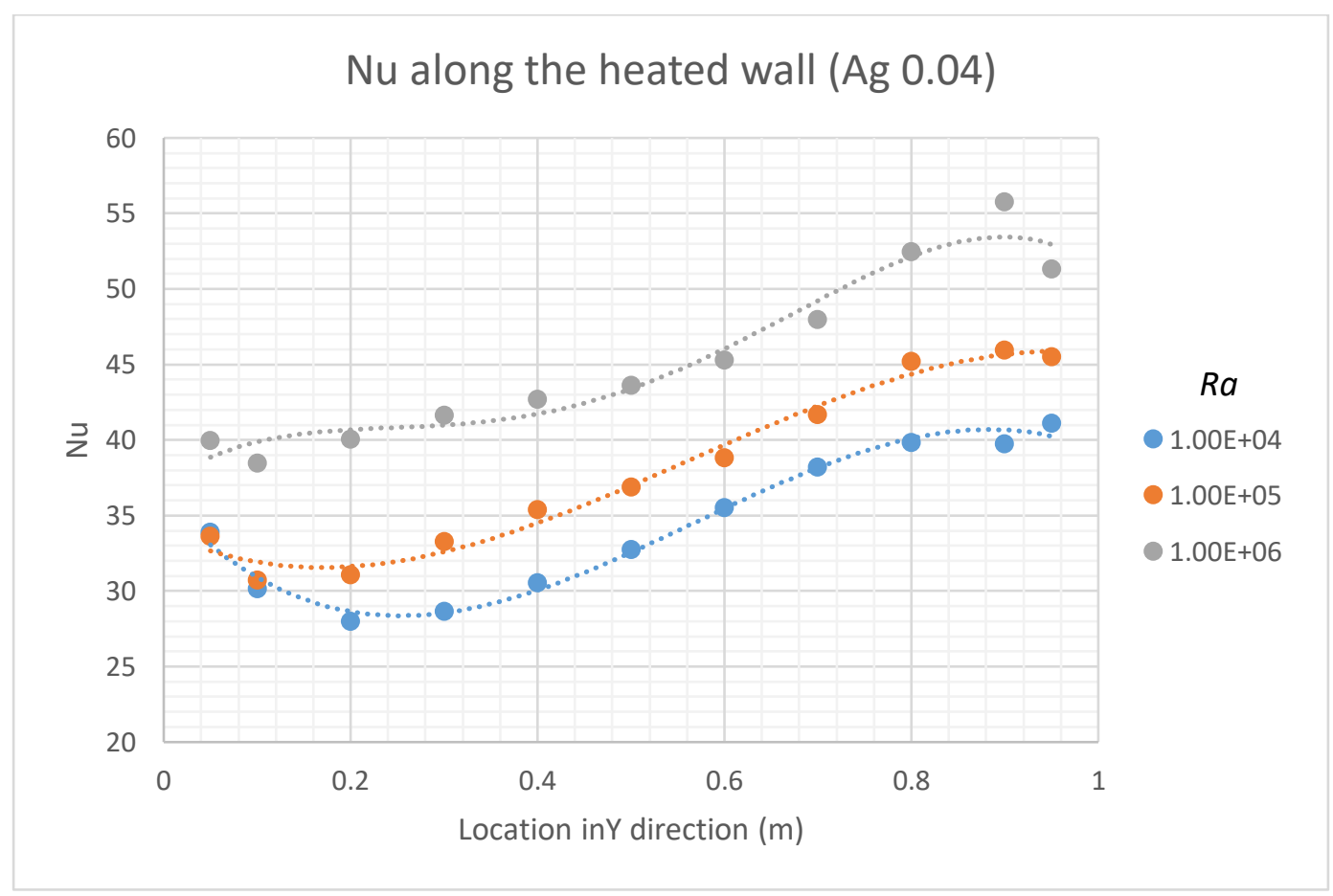

Fig 9. Nusselt numbers along hot wall for silver-water nanofluid, P1 flux with $\Phi=0.04$ for different Rayleigh numbers. 


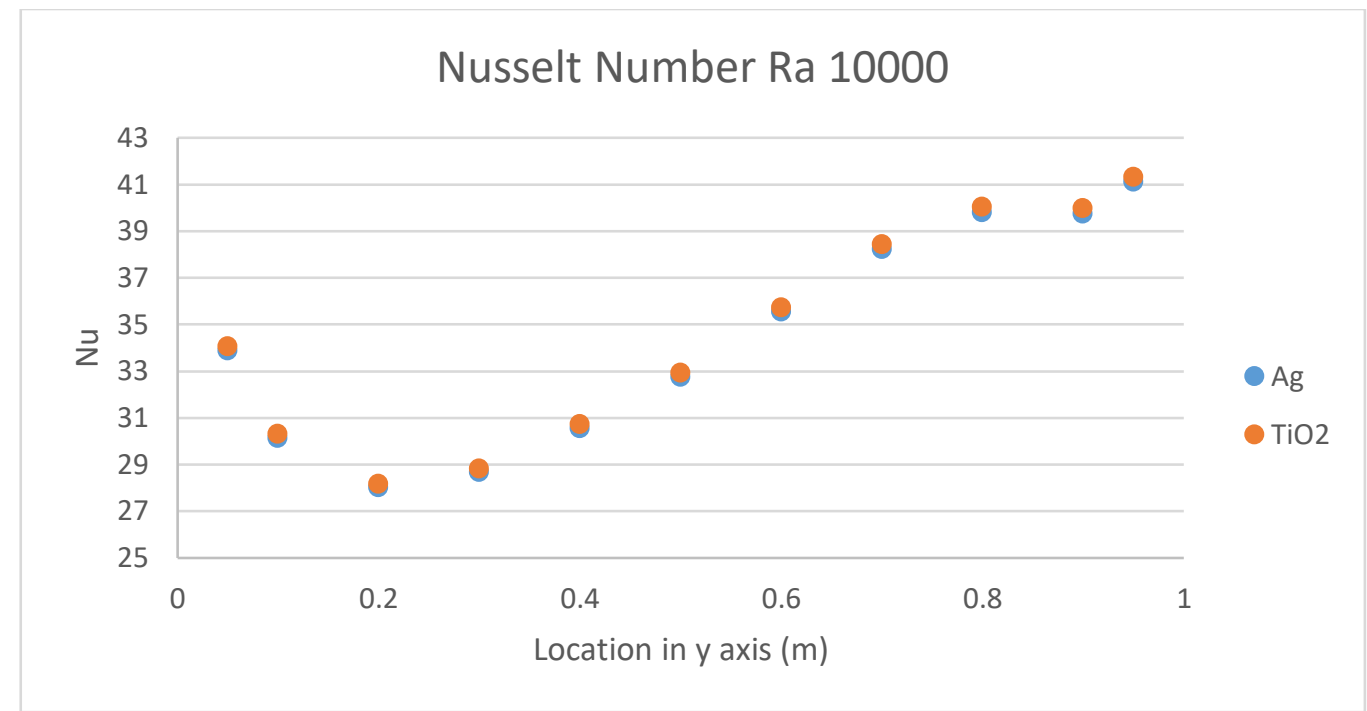

Fig 10. Nusselt numbers for different nanofluids, P1 flux with $\Phi=0.04, R a=10^{4}$.

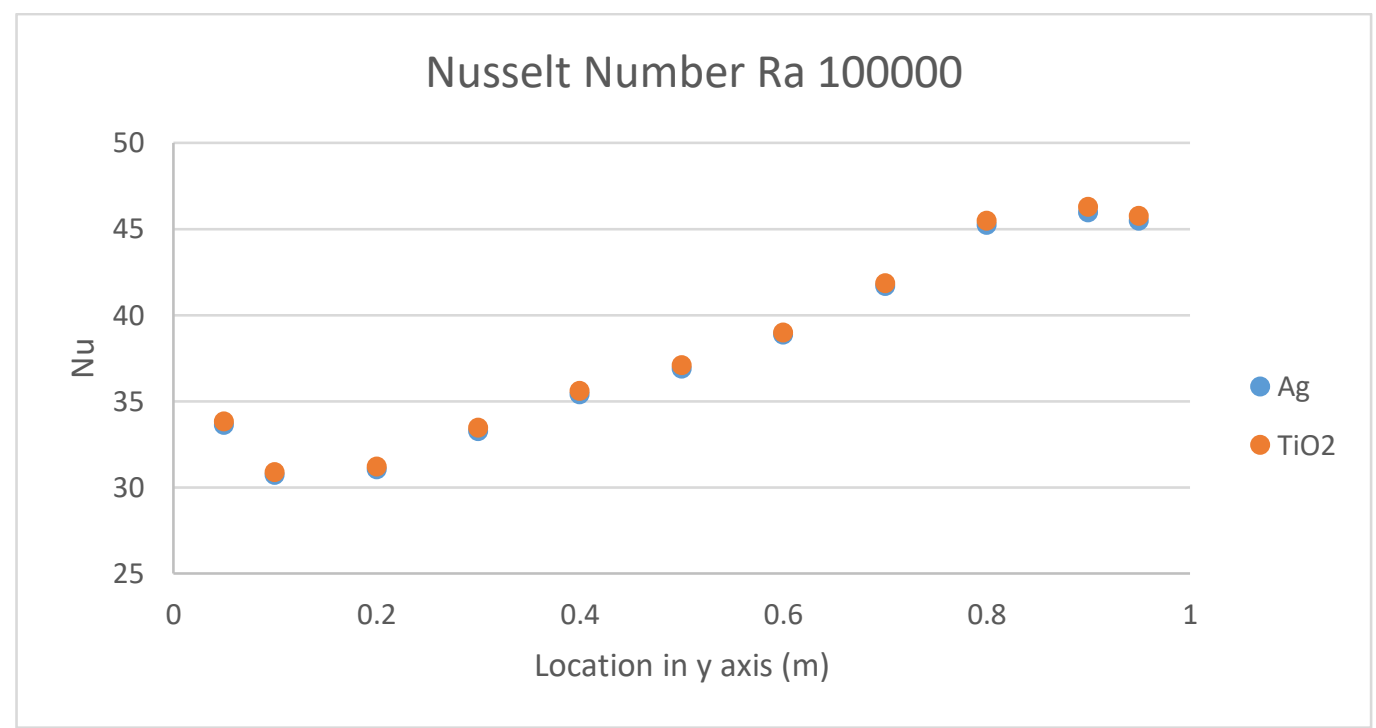

Fig 11. Nusselt numbers for different nanofluids, P1 flux with $\Phi=0.04, R a=10^{5}$.

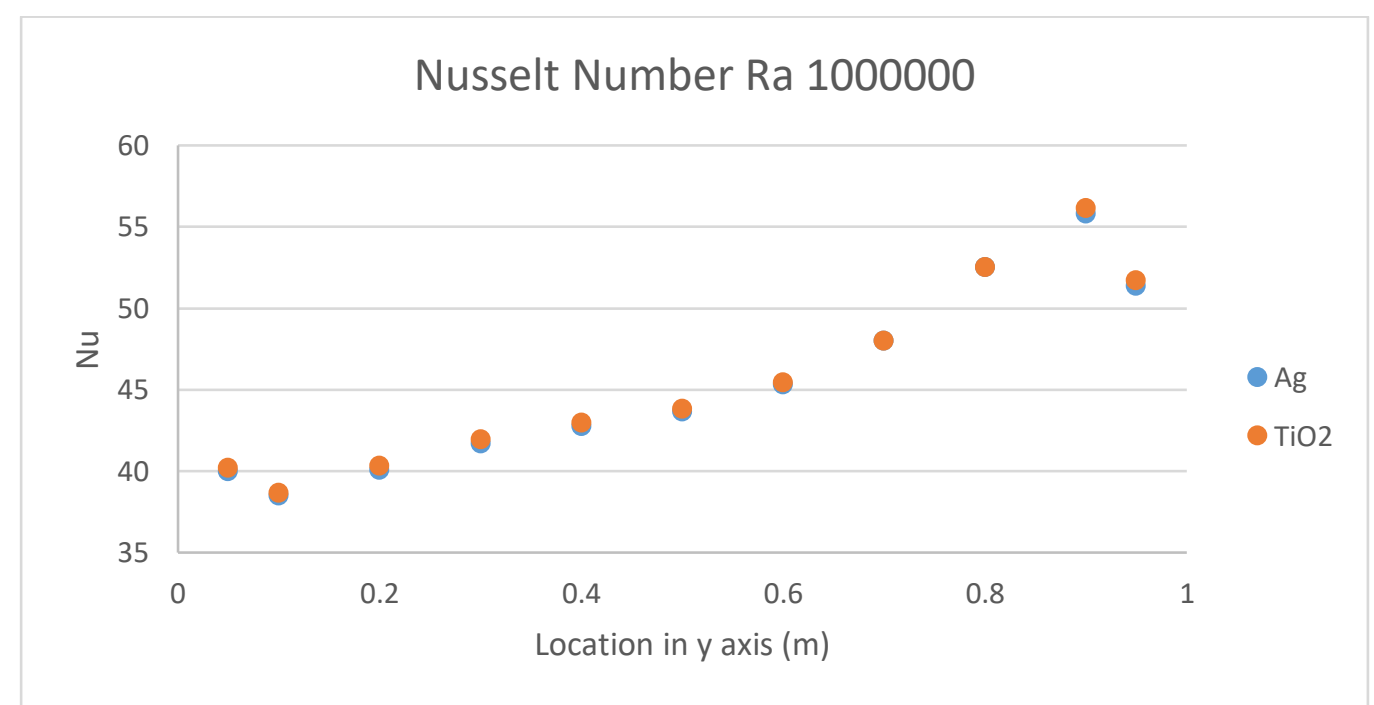

Fig 12. Nusselt numbers for different nanofluids, P1 flux with $\Phi=0.04, R a=10^{6}$. 


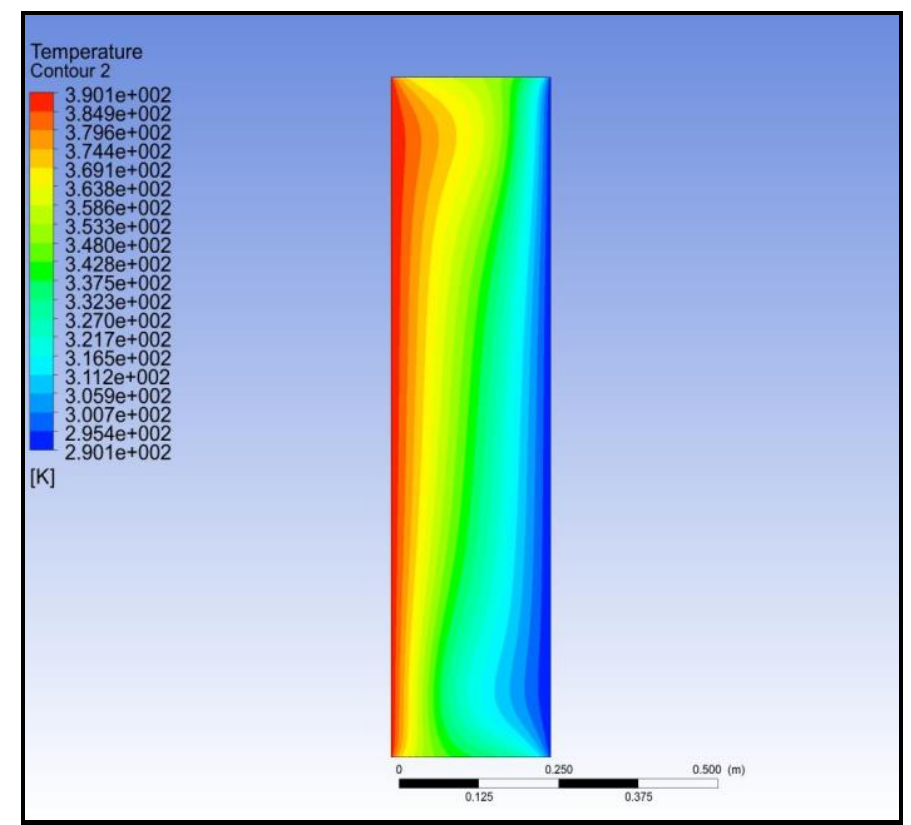

Fig 13. Isotherms for Titanium oxide-water nanofluid, $P 1$ flux with $\Phi=0.04, R a=10^{5}$ and absorption coefficient of 0.2 for aspect ratio $A R=4$ (tall enclosure).

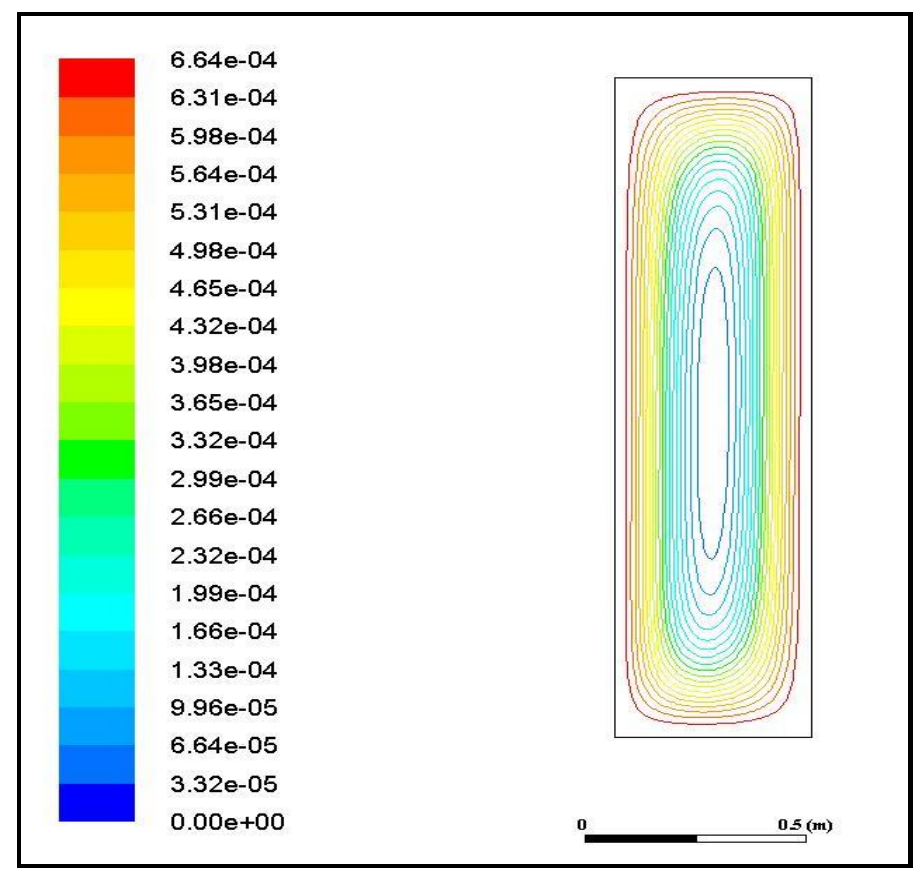

Fig 14. Streamlines for Titanium oxide-water nanofluid, $P 1$ flux with $\Phi=0.04, R a=10^{5}$ and absorption coefficient of 0.2 for aspect ratio $A R=4$. 


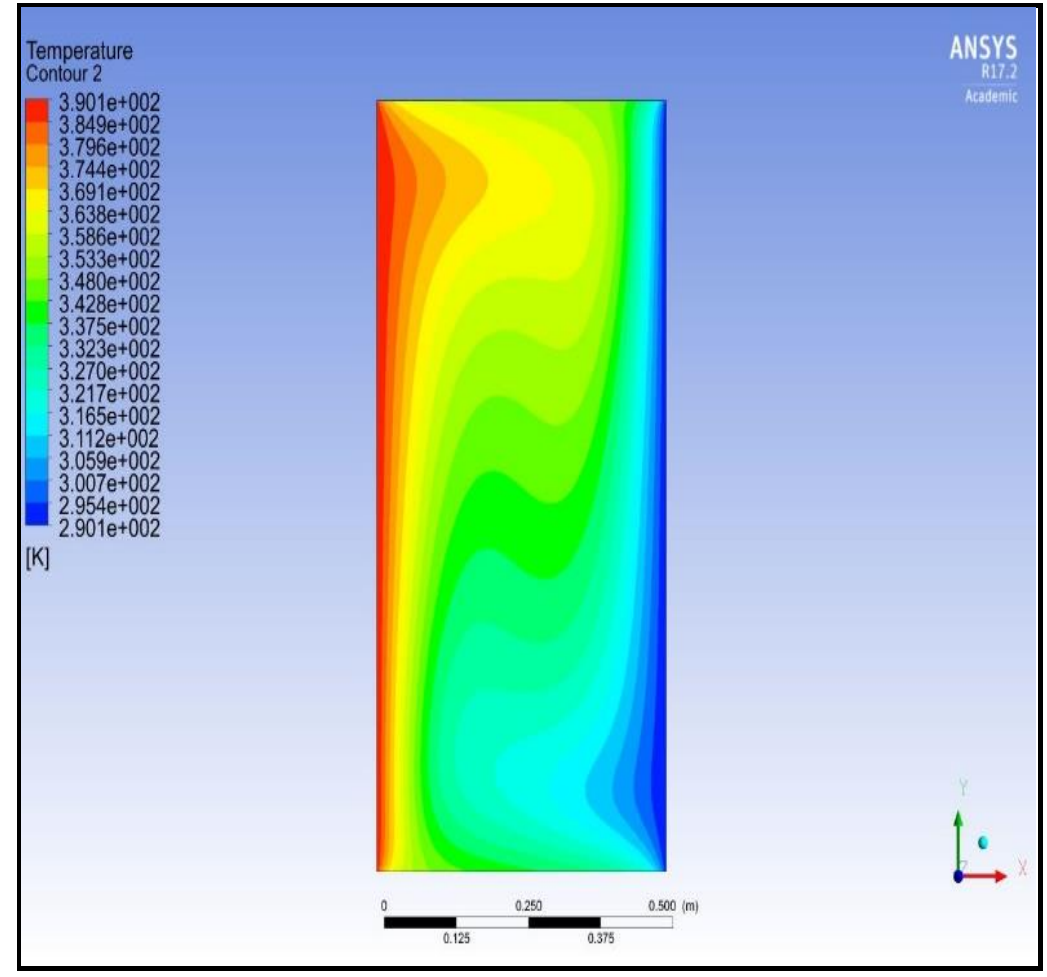

Fig 15. Isotherms for Titanium oxide-water nanofluid, $P 1$ flux with $\Phi=0.04, R a=10^{5}$ and absorption coefficient of 0.2 for aspect ratio $A R=2$.

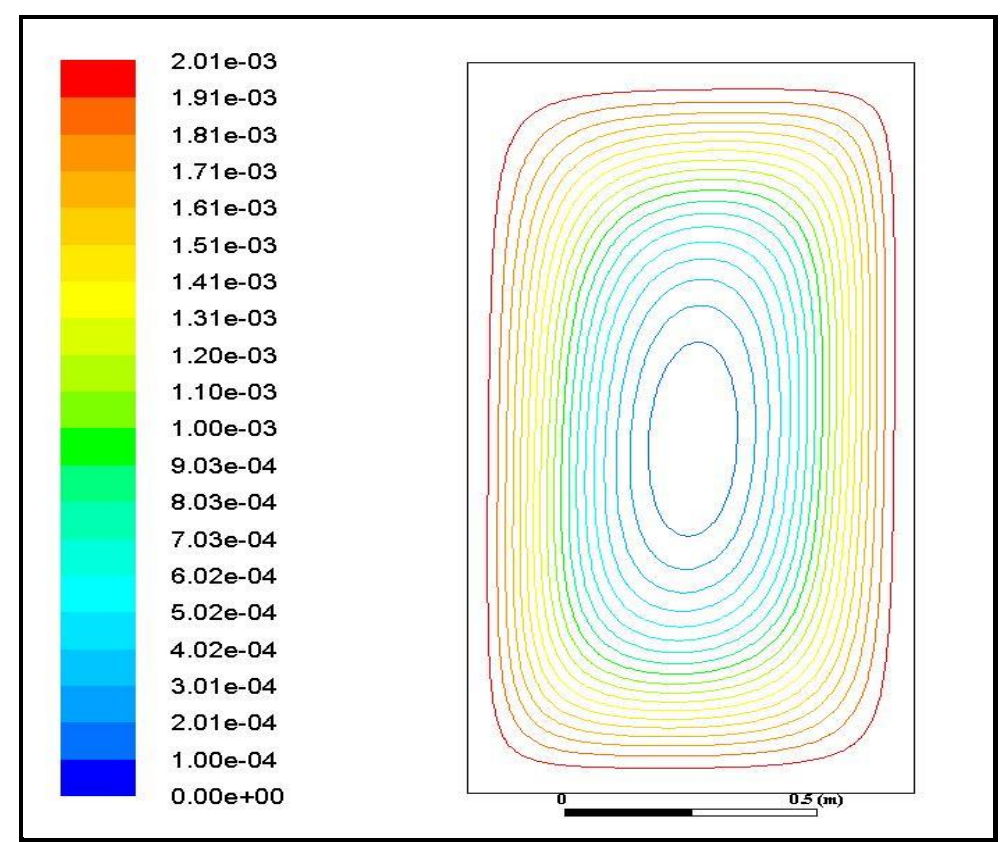

Fig 16. Streamlines for Titanium oxide-water nanofluid, Pl flux with $\Phi=0.04, R a=10^{5}$ and absorption coefficient of 0.2 for aspect ratio $A R=2$. 


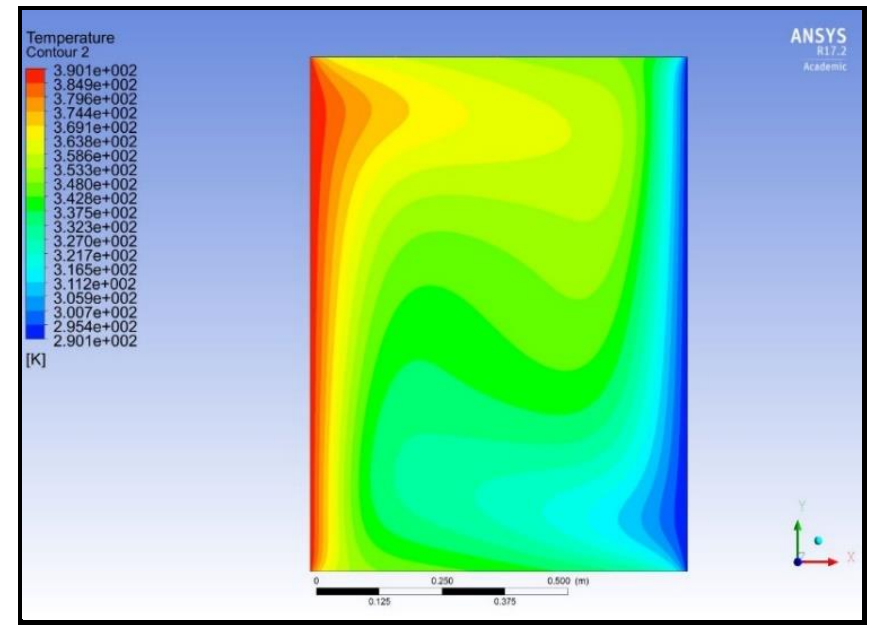

Fig 17. Isotherms for Titanium oxide-water nanofluid, $P 1$ flux with $\Phi=0.04, R a=10^{5}$ and absorption coefficient of 0.2 for aspect ratio $A R=4 / 3$.

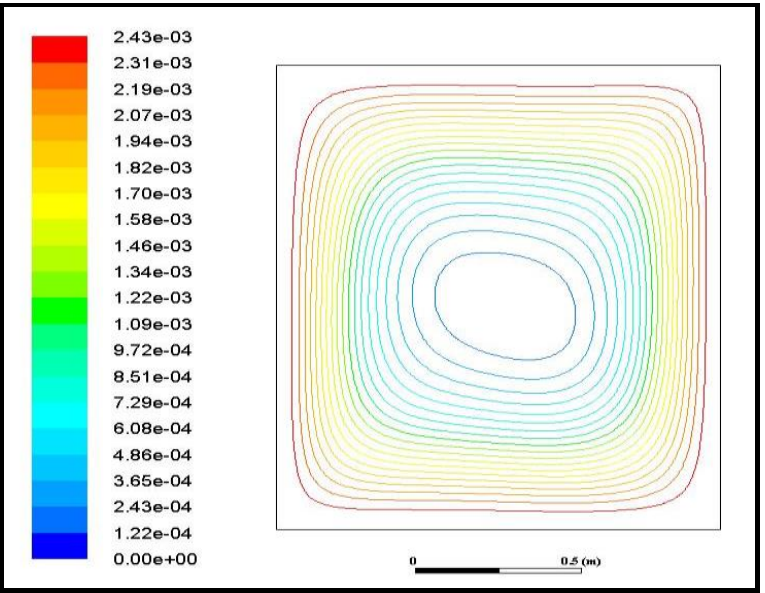

Fig 18. Streamlines for Titanium oxide-water nanofluid, P1 flux with $\Phi=0.04, R a=10^{5}$ and absorption coefficient of 0.2 for aspect ratio $A R=4 / 3$.

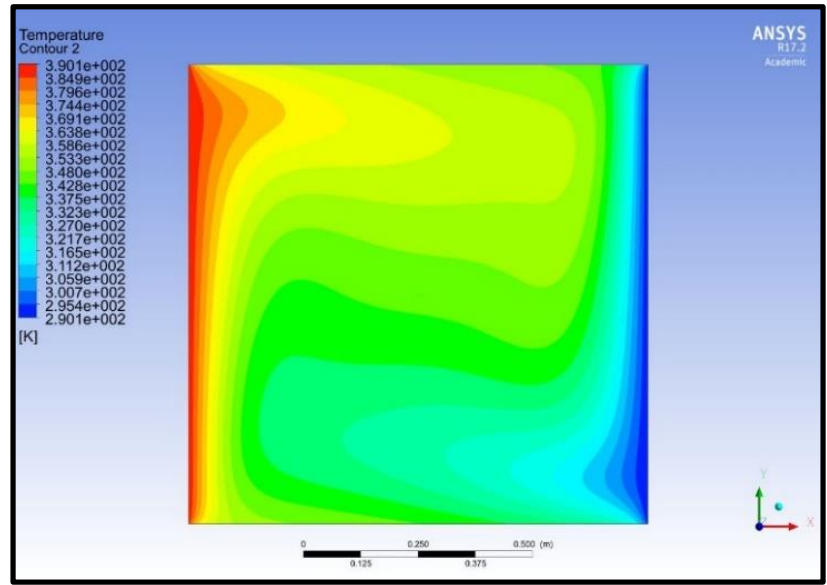

Fig 19. Isotherms for Titanium oxide-water nanofluid, $P 1$ flux with $\Phi=0.04, R a=10^{5}$ and absorption coefficient of 0.2 for aspect ratio $A R=1$ (square cavity). 


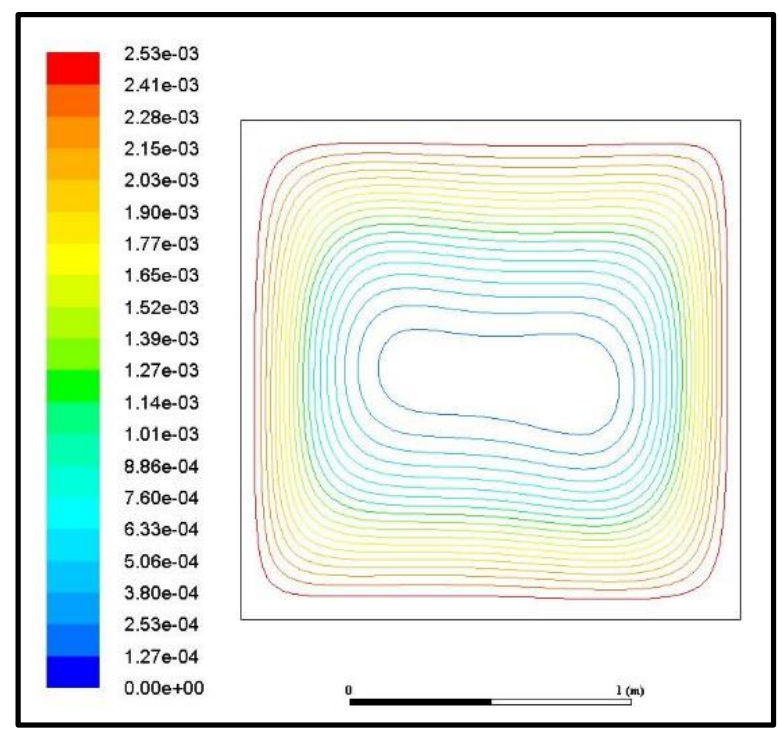

Fig 20. Streamlines for Titanium oxide-water nanofluid, P1 flux with $\Phi=0.04, R a=10^{5}$ and absorption coefficient of 0.2 for aspect ratio $A R=1$ (square cavity).

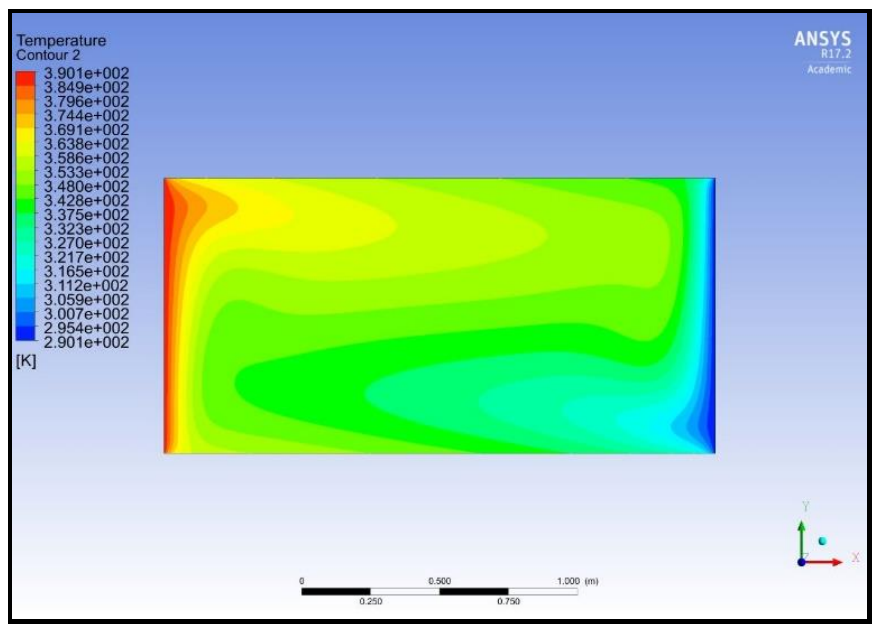

Fig 21. Isotherms for Titanium oxide-water nanofluid, P1 flux with $\Phi=0.04, R a=10^{5}$ and absorption coefficient of 0.2 for aspect ratio $A R=0.5$ (shallow cavity).

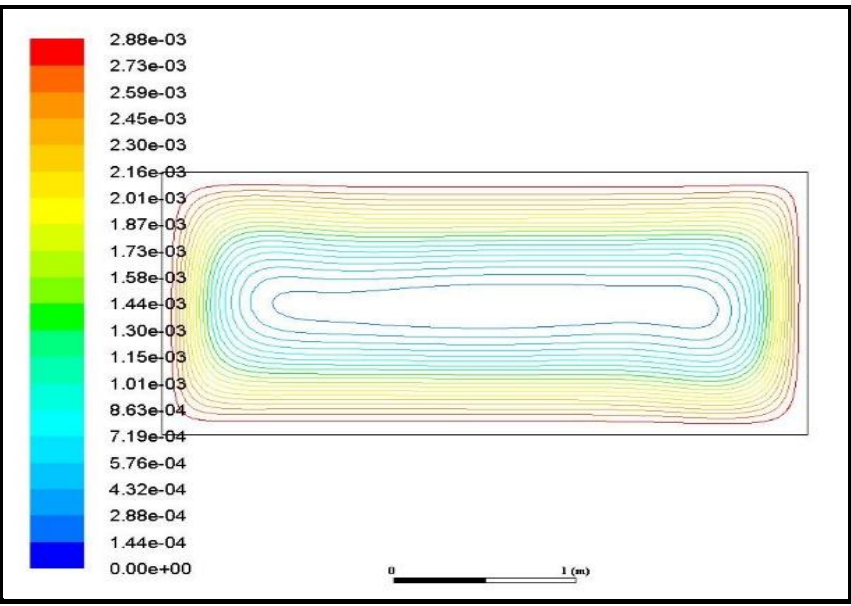

Fig 22. Streamlines for Titanium oxide-water nanofluid, P1 flux with $\Phi=0.04, R a=10^{5}$ and absorption coefficient of 0.2 for aspect ratio $A R=0.5$ (shallow cavity). 


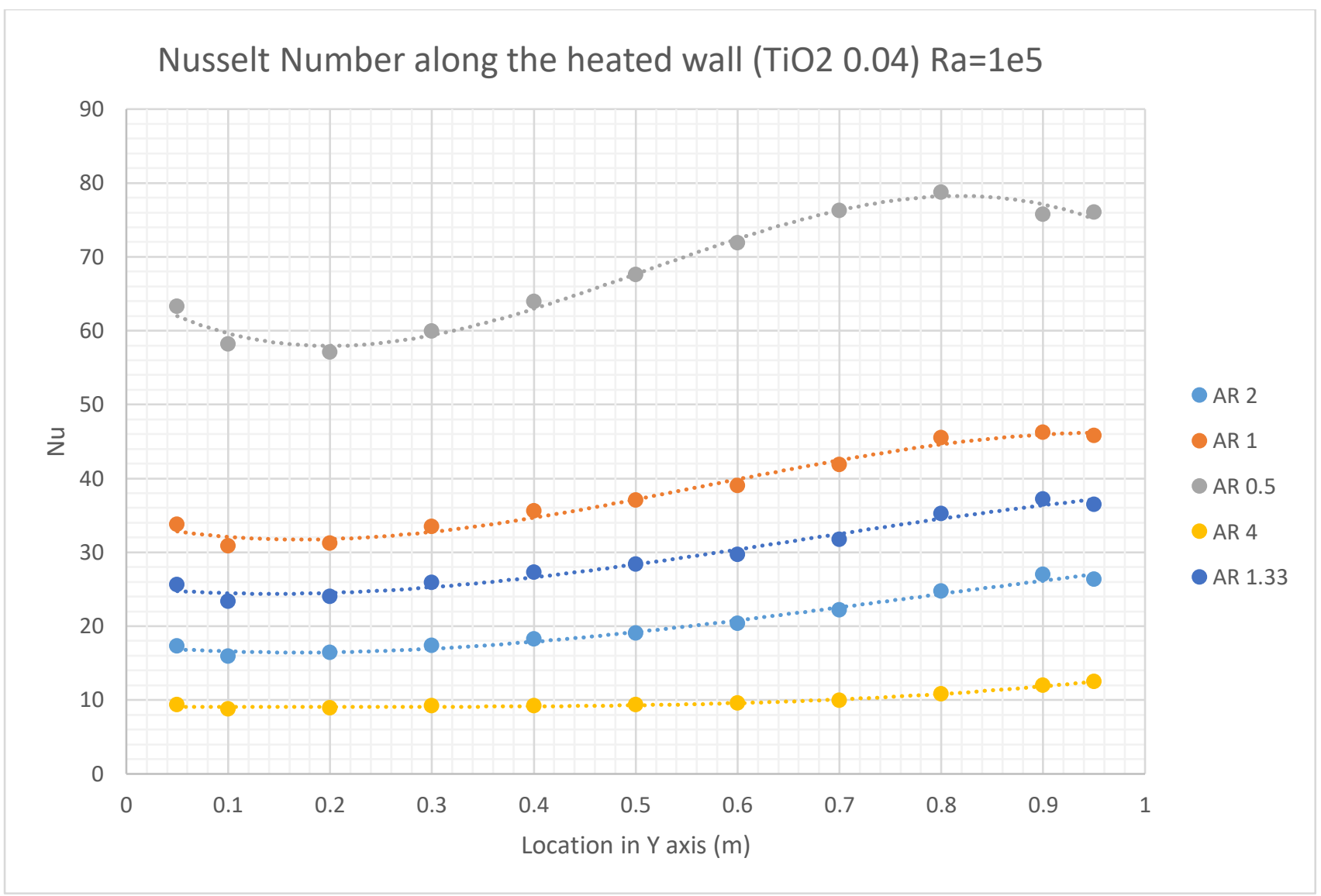

Fig 23. Nusselt numbers along hot wall for Titanium oxide-water nanofluid, P1 flux with $\Phi=0.04$, $R a=10^{5}$ with different enclosure aspect ratios (AR). 
APPENDIX - NANO-PARTICLE PROPERTIES (TITANIUM OXIDE COPPER, SILVER)

\begin{tabular}{|c|c|c|c|c|c|}
\hline \multicolumn{2}{|c|}{$\mathrm{TiO}_{2}$} & \multicolumn{2}{c|}{$\mathrm{Cu}$} & \multicolumn{2}{c|}{$A g$} \\
\hline$V_{n p}$ & 1 & $V_{n p}$ & 1 & $V_{n p}$ & 1 \\
\hline$V_{f}$ & 100 & $V_{f}$ & 100 & $V_{f}$ & 0 \\
\hline$\Phi$ & 0.01 & $\Phi$ & 0.01 & $P_{f}$ & 997.1 \\
\hline$P_{f}$ & 997.1 & $P_{f}$ & 997.1 & $P_{s}$ & 10500 \\
\hline$P_{s}$ & 4250 & $P_{s}$ & 8933 & $P_{n f}$ & 1092.129 \\
\hline$P_{n f}$ & 1029.629 & $P_{n f}$ & 1076.459 & $C_{p f}$ & 4179 \\
\hline$C_{p f}$ & 4179 & $C_{p f}$ & 4179 & $C_{p s}$ & 235 \\
\hline$C_{p s}$ & 686.2 & $C_{p s}$ & 385 & $C_{p n f}$ & 3799.814025 \\
\hline$C_{p n f}$ & 4034.827682 & $C_{p n f}$ & 3864.154734 & $K_{s}$ & 429 \\
\hline$K_{s}$ & 8.9538 & $K_{s}$ & 401 & $K_{f}$ & 0.613 \\
\hline$K_{f}$ & 0.613 & $K_{f}$ & 0.613 & $K_{n f}$ & 0.619043619 \\
\hline$K_{n f}$ & 0.617981786 & $K_{n f}$ & 0.619041831 & $u_{f}$ & $1.08 \mathrm{E}-03$ \\
\hline$u_{f}$ & $1.08 \mathrm{E}-03$ & $u_{f}$ & $1.08 \mathrm{E}-03$ & $u_{n f}$ & 0.001107275 \\
\hline$u_{n f}$ & 0.001107275 & $u_{n f}$ & 0.001107275 & $V_{n f}$ & $1.01387 \mathrm{E}-06$ \\
\hline$V_{n f}$ & $1.07541 \mathrm{E}-06$ & $V_{n f}$ & $1.02863 \mathrm{E}-06$ & & \\
\hline
\end{tabular}

Table 1: Properties of Titanium Oxide, Copper and Silver nano-particles at volume fraction $(\Phi)=0.01$ i.e. $1 \%$

\begin{tabular}{|c|c|c|c|c|c|}
\hline \multicolumn{2}{|c|}{$\mathrm{TiO}_{2}$} & \multicolumn{2}{c|}{$\mathrm{c}$} & \multicolumn{2}{c|}{$A g$} \\
\hline$V_{n p}$ & 4 & $V_{n p}$ & 4 & $V_{n p}$ & $V_{f}$ \\
\hline$V_{f}$ & 100 & $V_{f}$ & 100 & $\Phi$ & 100 \\
\hline$\Phi$ & 0.04 & $\Phi$ & 0.04 & $P_{f}$ & 997.1 \\
\hline$P_{f}$ & 997.1 & $P_{f}$ & 997.1 & $P_{s}$ & 10500 \\
\hline$P_{s}$ & 4250 & $P_{s}$ & 8933 & $P_{n f}$ & 1377.216 \\
\hline$P_{n f}$ & 1127.216 & $P_{n f}$ & 1314.536 & $C_{p f}$ & 4179 \\
\hline$C_{p f}$ & 4179 & $C_{p f}$ & 4179 & $C_{p s}$ & 235 \\
\hline$C_{p s}$ & 686.2 & $C_{p s}$ & 385 & $C_{p n f}$ & 2976.225708 \\
\hline$C_{p n f}$ & 3652.236718 & $C_{p n f}$ & 3147.706768 & $K_{s}$ & 429 \\
\hline$K_{s}$ & 8.9538 & $K_{s}$ & 401 & $K_{f}$ & 0.613 \\
\hline$K_{f}$ & 0.613 & $K_{f}$ & 0.613 & $K_{n f}$ & 0.636480004 \\
\hline$K_{n f}$ & 0.632452869 & $K_{n f}$ & 0.636473256 & $u_{f}$ & $1.08 \mathrm{E}-03$ \\
\hline$u_{f}$ & $1.08 \mathrm{E}-03$ & $u_{f}$ & $1.08 \mathrm{E}-03$ & $u_{n f}$ & 0.001195818 \\
\hline$u_{n f}$ & 0.001195818 & $u_{n f}$ & 0.001195818 & $V_{n f}$ & $8.68287 \mathrm{E}-07$ \\
\hline$V_{n f}$ & $1.06086 \mathrm{E}-06$ & $V_{n f}$ & $9.09689 \mathrm{E}-07$ & & \\
\hline
\end{tabular}

Table 2: Properties of Titanium Oxide, Copper and Silver nano-particles at volume fraction $(\Phi)=0.04$ i.e. $4 \%$ 